\title{
The Recent Progress in Modification of Polymeric Membranes Using Organic Macromolecules for Water Treatment
}

\author{
Saraswathi Nagandran ${ }^{1}$, Pei Sean Goh ${ }^{1, *}$, Ahmad Fauzi Ismail ${ }^{1, *}$, Tuck-Whye Wong ${ }^{2}$ and \\ Wan Rosmiza Zana Binti Wan Dagang ${ }^{3}$ \\ 1 Advanced Membrane Technology Research Centre (AMTEC), School of Chemical and Energy Engineering, \\ Faculty of Engineering, Universiti Teknologi Malaysia, Skudai 81310, Malaysia; \\ saraswathinagandran@yahoo.com \\ 2 School of Biomedical Engineering and Health Sciences, Faculty of Engineering, \\ Universiti Teknologi Malaysia, Skudai 81310, Malaysia; wongtuckwhye@utm.my \\ 3 Faculty of Science, Universiti Teknologi Malaysia, Skudai 81310, Johor, Malaysia; rosmiza@fbb.utm.my \\ * Correspondence: peisean@petroleum.utm.my (P.S.G.); afauzi@utm.my (A.F.I.); Tel.: +607-533-5807 (P.S.G.)
}

Received: 24 December 2019; Accepted: 31 January 2020; Published: 4 February 2020

check for updates

\begin{abstract}
For decades, the water deficit has been a severe global issue. A reliable supply of water is needed to ensure sustainable economic development in population growth, industrialization and urbanization. To solve this major challenge, membrane-based water treatment technology has attracted a great deal of attention to produce clean drinking water from groundwater, seawater and brackish water. The emergence of nanotechnology in membrane science has opened new frontiers in the development of advanced polymeric membranes to enhance filtration performance. Nevertheless, some obstacles such as fouling and trade-off of membrane selectivity and permeability of water have hindered the development of traditional polymeric membranes for real applications. To overcome these issues, the modification of membranes has been pursued. The use of macromolecules for membrane modification has attracted wide interests in recent years owing to their interesting chemical and structural properties. Membranes modified with macromolecules have exhibited improved anti-fouling properties due to the alteration of their physiochemical properties in terms of the membrane morphology, porosity, surface charge, wettability, and durability. This review provides a comprehensive review of the progress made in the development of macromolecule modified polymeric membranes. The role of macromolecules in polymeric membranes and the advancement of these membrane materials for water solution are presented. The challenges and future directions for this subject are highlighted.
\end{abstract}

Keywords: macromolecules; polymeric membranes; water treatment; modifications

\section{Introduction}

The shortage of fresh water caused by population growth, climate change, industrial development, energy plant and urbanization are the most critical challenge facing mankind today [1,2]. These anthropogenic activities introduce various organic and inorganic contaminants into the water systems [1,3]. Worsening the issue, only $2.5 \%$ of the water on Earth is safe for consumption and most of this freshwater is locked in the form of glaciers, icecaps and underground water [4]. Based on the current circumstances, it is predicted about 3.9 billion people will live in regions under conditions of severe water scarcity by 2030 [5]. To tackle the problems associated with water shortages and water stress in many regions, research has been focused on suitable alternative ways to acquire freshwater 
from existing water [6]. Several economical and multifunctional processes are developed to produce superior water and wastewater treatment resolutions.

Among them, membrane technologies are proving to be dominant tools for desalination and wastewater treatments because membrane filtration offers numerous advantages including simple operation, maintenance and monitoring, compact modular design and a lower footprint, lower mass storage tubes and feed systems and low flow rates of chemical sludge while generating high-quality water from a wide range of sources $[3,5,7]$. Membrane technology is known to be an effective water separation process due to its high contaminant rejection to yield high quality treated water [5]. Generally, the idea behind membrane-based wastewater separation is to remove suspended particulate matter and soluble components from the wastewater semi-permeable membranes. Two major filtrations, i.e., pressure driven, and osmotically driven processes have been commonly used for the separation. For the past few decades, the enthusiasm for the application of membrane technology has increased significantly, especially in the water industry, which has led to a number of attempts by membrane scientists.

The main goal of recent research on polymeric nanocomposite membranes development for sustainable water purification is to enhance the fouling resistance and overcoming the tradeoff between water permeability and salt rejection [8-12]. The significance of polymer nanocomposite is acknowledged by number of outstanding performances such as high flexibility, reduced storage space, mechanical and chemical stability, film forming capacity, permeability, chemical species selectivity and a high removability of wastewater product. Thus, advances in nanotechnology have offered leapfrogging opportunity to the next-generation water supply systems to improve the conventional technologies with a more affordable price [13]. In this regard, nanomaterials (at least one dimension smaller than $100 \mathrm{~nm}$ ) play an integral role in membrane technologies and these properties were critically analyzed for their functions in membrane technology processes [13]. Nanoscale materials have an enormous surface area and special versatile size-dependent properties that are feasible for water treatment applications. The embedment of nanomaterials in the polymer matrix is a promising strategy to enhance the efficiency and physiochemical characteristics of the resulting nanocomposite membranes so that the separation properties in terms of flux and rejection as well as anti-fouling properties can be enhanced [14]. Many studies have focused on the development of novel nano-scaling additives [15-18]. Several studies have shown that nanoparticles (NPs), nanotubes, nanofibers, or nanosheets are endowed with large specific surface area, high reactivity, unique physical and chemical properties and some of them have strong antimicrobial properties $[19,20]$. Some well-studied antimicrobial nanomaterials include silver (Ag) [21,22], carbon nanotube (CNT) [23-25], graphene and graphene oxide [26-28], gold [29], copper [30], zinc oxide [31] and titanium oxide [32], and zeolite [33].

Nonetheless, most nanomaterial applications are still in the laboratory research phase for water treatment. Most unmodified inorganic nanomaterials are likely to aggregate and are incompatible with the polymer matrix and therefore susceptible to defects with a poor separation efficiency $[5,34,35]$. Particularly because of the high-surface energy nanomaterial and high-interaction between particles, aggregation is one of the major problems in the production of nanocomposite membranes. The aggregation not only inhibits homogeneous dispersion of nanomaterials in the solvent used for membrane substrates and active layer formation, but also enlarges membrane micro-voids and reduces effective nanomaterials surface area. To optimize nanofiller stability in the host polymer, it is vital to establish the adhesive interface compatibility between the two phases.

Most nanoparticles are high cost and the processing of nanoparticles requires steps that are poor in reproducibility [36]. Currently, the environmental side effects of the use of nanomaterials have not been systematically concluded. The leaching of these nanomaterials into the treated water may affect human health [19,37]. For instance, while graphene, carbon nanotubes, silver and gold have shown great potential in desalination, the comparative high costs and environmental safety uncertainty due to present cytotoxicity to human and animal cells could reduce their broad range of applications [38-40]. While it is crucial that the membrane is reproducible and cost-effective, the long-term stability of the nanocomposite membranes under realistic testing condition is also a 
significant element, whereby long-term testing of the stability of the nanocomposite membrane are crucial in order to control nanomaterials leaching, particularly for surface-modified nanocomposite membranes [41,42]. Surface modification through coating of nanomaterials on the membrane surface is not favorable as the adhesion is poor due to absence of chemical interaction with polymeric matrix. Thus, the nanomaterials can be lost in the filtration process, which not only affects the membrane performance but can also contribute to the secondary contamination of the water [43].

Research interest in modification of polymeric membranes using macromolecules has attracted both industrial and academic interest. Generally, macromolecules are formed by linking the monomer molecules (e.g., amide, monosaccharides) together through chemical reactions known as polymerization [44]. The architecture and shape of macromolecules are an important microstructural feature which associate with the way of branch molecules point out from the main chain. The macromolecular structure is regulated by basic principles of chemistry such as covalent bonds and polarity, bond rotation and vibration, non-covalent interactions, hydrophobic effects, and molecular structure dynamic aspects. For instance, the linear growth of the chains may produce conventional linear polymers that follow different molecular conformations [45]. Alternatively, by repetitive monomeric units branching, hyper-branched polymers can be used to generate high density surface-group polymers. These structures play a crucial role in determining the physical properties of macromolecules and affecting flexibility.

Macromolecules such as dendrimers/hyperbranched polymers, block copolymer micelles and supramolecular assemble nanoparticles are becoming the essential candidates for the preparation of water separation membranes. Due to their unique structure and flexible backbone, organic nanoparticles become versatile and compatible with the membrane of the polymer matrix. Currently, simple and controllable methods have also been established for synthesizing organic functional nanomaterials. In view of the importance of this topic, this contribution provides an extensive review of advances and developments of introducing a wide range of macromolecules into the selective layer, substrate and surface of polymer membranes. The main objectives of this review paper are to succinctly review recent progress of modified polymeric membranes using macromolecules as a modifier and summarize the current state of knowledge of the membranes for water treatment application. In view of the rapid progress made in this field, the representative studies discussed in this manuscript are mainly based on the literature published in the last five years. The significant roles played by macromolecules in polymeric membrane and the advancements of these modified membranes for wastewater application are critically reviewed. There is also critical discussion of the major challenges, the potential directions and perspectives for the design of macromolecule-incorporated into polymeric membrane. This study will encourage further studies to tackle current membrane design problems and introduce practical applications of membranes in order to improve membrane performance.

\section{Membrane and Membrane Processes}

Membrane processes can be categorized based on various parameters such as the structure of the membrane, membrane material type, driving strength and separation mechanism, as well as the size range of extracted constituents. In general, the filtration membranes have been divided into four categories: microfiltration (MF), ultrafiltration (UF), nanofiltration (NF) and reverse osmosis $(\mathrm{RO})$ with reduced pore size in order to reject various size substances and effluences [46]. Among these pressure-driven membrane technologies, $\mathrm{RO}$ has gained great global interest and one of the promising large-scale processes due to the simplicity in plant design with low energy cost $[47,48]$. RO technology, which consists of only four major processes, offer high performance of semi-permeable membrane that leads to superior water permeability and salt rejection [49-52]. Alternatively, membrane distillation (MD) and forward osmosis (FO) are the emerging technologies have been developed to treat challenging wastewater or high salinity water. Due to an absence of hydraulic pressure, both MD and $\mathrm{FO}$ are known to be less energy extensive options and refrain from severe fouling compared to RO [53]. The membrane modifications for these technologies have been widely reported [54-56]. 
Polymeric membranes dominate a very broad range of both academic and industrial interest due to following advantages; (i) various types of polymer materials are marketable; (ii) a wide variety of selective barriers can be generated using a flexible and robust system, namely pore, not porous, loaded and affinity; (iii) large-scale production of stable industrial-scale performance membrane at reasonable cost based on efficient production processes; (iv) production of different types of membrane shape (flat sheet, hollow fiber, capillary or tubular). Polysulfone (PSf), polyethersulfone (PES), polyamide (PA), polyacrylonitrile (PAN), and polyvinylidene fluoride (PVDF) are commonly used polymeric membrane materials for wastewater treatment and desalination $[57,58]$. Improvements in polymer membrane materials in terms of fouling resistance and quality are important for further improvisation, as current polymeric membrane technology still suffers from fouling and frequent membrane replacement, leading to high membrane system life cycle costs [54]. Polymeric membrane can be classified into two groups based on membrane structures: asymmetric membranes and thin film composite (TFC) [59]. Asymmetric membrane is synthesized by the phase inversion method using the same polymer for both the thin skin layer and the porous sublayer. The most common polymers that have been used for prepared asymmetric membrane are cellulose acetate, cellulose diacetate, triacetate, and their blend [60], while the typical TFC membranes are fabricated thin film of polyamide layer known as active layer on top of a microporous support layer of polysulfone (provide mechanical strength and stability) through interfacial polymerization process between trimesoyl chloride (TMC) and m-phenylenediamine (MPD) [61,62]. TFC polyamide membrane has attracted considerable attention in research and industrial areas compared with cellulose membranes due to its excellent performances in separation, high rejection of undesired compounds, high filtration rate, good mechanical strength and flexibility to select and optimize material to form a microporous substrate and a thin selective layer of film [61-64].

Despite the promising performances rendered by membrane technologies, most polymer membranes experience fouling problems when micro-organism and organic substances such as protein and water source polysaccharides are deposited on a membrane surface or inside a membrane pore because of their hydrophobicity [65]. It impedes water permeation, decreases the flux, increases the complexity of operation and reduces membrane lifespan, resulting in higher costs [5,66,67]. Membranes are affected by four main types of foulants, namely: (a) inorganic/crystalline, (b) organic, colloidal, (c) microbiological or biofouling and (d) particulate [68-70]. Among these, biofouling is the major problem because it reduces the efficiency of the system and also contributes to high economic and environmental costs of operating by attachment and proliferation of microorganisms on the surface of membrane [71-73]. Therefore, many efforts have been implemented to prevent fouling problems, namely pre-treatment, cleaning-in-place, and membrane modifications [74,75].

Pre-treatment with chlorine derivatives disinfectant can effectively retard the growth of bacteria. Nonetheless, after exposure to chlorine, the surface of polyamide is known to suffer from decomposition and the chlorine in feed water needs to be extracted before passing through membrane, thus this is not an effective way to control biofouling. In comparison, membrane cleaning is a common treatment of biofouling, but the pre-cleaning condition rarely restores membrane efficiency. In addition, the harsh cleaning procedure is often related to shorter membrane life and closer to membrane replacement. Therefore, membrane modification is a more preferable method compared to other methods because this effort has great potential to improve membrane structure and surface properties of commercially available membranes. Surface modification is divided into two groups based on the interaction between membrane and modifier: chemical modification and physical modification. In physical modification, the hydrophilic additives interact physically on the polymer membrane surface, but not with covalent bonding. This modification can be performed through two approaches, i.e., (i) the coating of deposition of the hydrophilic polymer on the membrane surface or (ii) a solution of chemically active monomers is first immersed or coated by the polymeric membrane. Then, by crosslink or polymerization reaction, they are immobile on the surface of the membrane without disrupting the chemical structure of the base membrane. In chemical modification, the polymeric membrane is modified through the formation 
of new chemical bonding. Commonly, the surface base polymer chain is first activated through chemical reaction or high-energy radiation prior to the introduction of new functionalities. Membrane modifications through both physical and chemical approaches allow the membrane surface properties such as surface wettability, pore size, surface roughness, and charge density to be tailored without affecting the bulk characteristics of the membranes [76,77]. For instance, by incorporating organic material into the membrane matrix, the hydrophilicity of a polymer membrane would be improved, with a decreased surface roughness and an enhanced charge property. Therefore, in order to address these issues, many researchers have focused on effective methods to control fouling by designing antifouling membranes with high permeability and rejection.

\section{The Role of Macromolecules in Polymeric Membrane}

Comprehensive work has been carried out to alter polymer membranes with macromolecules to address the challenges of membrane flux, fouling, wetting porosity and mechanical strength [20]. Macromolecules are derived from multiple repetitions of units of low molecular mass of molecules known as monomers that are linked together via chemical interaction [78]. Macromolecules have received special attention due to their characteristics such as unique molecular shape, leading to intrinsic particular physicochemical characteristics, molar mass, chemical structure of the chain segment, intra and intermolecular interactions and chain flexibility which make them suitable for membrane technology. The chemical structure of the side groups and primary chain affects the flexibility of the macromolecule chain [44]. In 1926, Herman Staudinger was first to present three main types of macromolecular architecture, such as linear, cross-linked and branched, which were then used as benchmark to forecast possible phenomena in new properties and synthetic structures [79]. Macromolecules including dendrimers [80-83], quaternary ammonium compounds (QAC) [84-86], polyzwitterions [87-89], chitosan [90-92], and cellulose [93-95] which are some of the common molecules that enhance the conventional membrane properties for water filtration application.

The unique structure of dendrimers offers host-guest chemistry broad opportunities such as the nanoscope size, a spherical layer, a ramified structure, open interior cavities and particle-like topography with various end groups and is especially well-equipped for multivalent interactions [96,97]. Therefore, these features make dendrimers well compatible between dendrimers and polymer networks [97]. The coating of dendrimers improved the hydrophilicity of the surface without affecting salt rejection, and the permeate flux reduction [98]. In addition, QACs are antimicrobial compounds that act by blocking bacterial enzymes and cell membranes by positive-charged polymers and by attributing antimicrobial activity to the QACs by molecular weight and the length of the $\mathrm{N}$-alkyl chain [99]. Therefore, surface modification of membranes using QAC would improve anti-fouling performance. Zwitterionic-based coatings also have a potential to improve biofouling stability of PA membranes.

Moreover, affinities, microstructure, electrostatics, and dispersion forces are the main factors that lead to the interaction between water molecules and the membrane interface [100]. The advantage of increasing hydrophilicity is that the pressure required for the transport of water across the membrane can be decreased, thus saving energy. For instance, the modified polymeric membrane using macromolecules which contribute to hydrophilicity balances with associated affinities result in highly efficient transport and also better selectivity. Confined geometries like pore network membranes play an additional role where they affect not only affinities, but also the movement of fluid and the selective materials through the membranes. The cationic groups act as antimicrobial agent (e.g., quaternary ammonium, phosphonium) which induce the electrostatic interaction between bacteria and these cations group, and eventually damage the bacteria cell [101].

The surface modification of pre-formed membranes is regarded as an effective and potential way of enhancing performance over their bulk counterpart, for example making conventional polymeric membranes hydrophilic. This can be done through various methods, including homogeneous blending, surface grafting, plasma treatment, surfactant methods, surface coating with hydrophilic polymers, gamma ray, UV irradiation and cross-linking as well as surface segregation methods with amphiphilic 
block copolymers [65]. Using a 'tailored' macromolecular structure, two methods can be chosen to achieve unique surface properties; (i) produce the membrane from a special functional polymer or (ii) use such functional polymer as a part of a blend or as an additive during membrane formation [102]. In the first approach, and in order to improve its properties and functionalities, monomers are chemically bound with the core polymer (e.g., graft polymerization). In the second approach, blend using an established 'matrix polymer' and 'functional polymer' would be highly attractive from the membrane preparation aspect. Polymer blending is a simple and economical method usually employed to improve hydrophobicity of the surface membrane [103].

Several published works indicate that the efficient layout of the macromolecules-modified membrane can theoretically monitor changes in the microstructure by taking on essential aspects of process variables $[104,105]$. This transition would facilitate improved mechanical stability of the membrane, microstructures of the membrane and the hydrophobic-hydrophilic equilibrium between the resulting modified membranes and will contribute ultimately to a significant improvement in membrane permeability and fouling mitigation. Recently, much research has been done using macromolecules or modifies to deal with obstacles such as salt rejection, water flux, and tendency of membrane fouling. The latest papers on polymeric membrane components provided novel manufacturing techniques, enhanced membrane growth circumstances, new composites or material combinations to incorporate their competitive benefits, sophisticated structural modification techniques for membranes, and the difficulties and/or disadvantages of the latest polymeric membranes [54,106].

\section{Modifications of Membrane Using Macromolecules}

\subsection{Dendrimers}

Dendrimers are a special class of branching polymers that are differentiated by well-defined global macromolecules assembled around a core unit. Dendrimers have attracted worldwide attention due to its unique properties of structural features such as low viscosity, high solubility, nanoscale size, compact molecular structure and a bulk number of functional groups [107-109]. Based on structural differences, dendritic polymer can be classified into six subclasses namely dendrimer, multi-arm star polymer, hyperbranched polymer, hypergrafted polymer, dendrigrafts polymer and dendritic-linear block polymer [110]. Dendrimers are mostly used in water purification among these groups. The most common dendrimers that used as modifier in polymer membrane are poly(amidoamine) (PAMAM) dendrimer. Recently, poly(propylene imine) (PPI) dendrimers, polyether-copolyester (PEPE) dendrimers and polyethylene glycol (PEG)ylated dendrimers have also been actively studied [111]. Table 1 summarizes the membrane performance in terms of flux and rejection as well as their advantages and limitations. This class of macromolecules is designed for unique nanostructured materials for various applications because of the flexibility of branching units connected to their chemical constitution and the ability to functionalize chain ends using several chemical groups. Poly (amidoamine) (PAMAM) is one of the most widely used dendrimers and is composed of repetitively branched subunits of amine and amine functionality as illustrated in Figure 1a. Each outward repeating cycle, known as a generation, is synthesized by divergent methods (Figure $1 b$ ) whereby it increases the number of generations that would lead to a change in the shape, size and the flexibility of PAMAM [108].

Dendrimers play an important role as outstanding adsorbents of inorganic and organic contaminate removal from wastewater. As a result of its strong internal and external distribution and its enlarged network of peripheral functional molecules, peripheral functional groups are changed by definition of target pollutants and grafted in high areas resulting in high selectivity and capacity [82,110]. PAMAM dendrimers are commonly used as adsorbents compared to other dendrimers because it consists of three fundamental components with high affinity to interact with target contaminants by capturing heavy metal ions, which are repeating units, ethylenediamine core, and terminal units. 
Table 1. Summary of the membrane performance in terms of flux and rejection as well as their advantages and limitations.

\begin{tabular}{|c|c|c|c|c|}
\hline \multirow{2}{*}{$\begin{array}{c}\text { Monomers Used/Thin } \\
\text { Film Composite(TFC) } \\
\text { Membranes }\end{array}$} & \multicolumn{2}{|c|}{ Performance Evaluation } & \multirow[b]{2}{*}{ Features } & \multirow[b]{2}{*}{ Reference } \\
\hline & $\begin{array}{l}\text { Water Permeability } \\
\left(\mathrm{L} / \mathrm{m}^{2} \text { bar }\right)\end{array}$ & Rejection (\%) & & \\
\hline $\begin{array}{l}\text { Piperazine + } \\
\text { PAMAM/trimesoyl } \\
\text { chloride }(\mathrm{TMC})\end{array}$ & $\begin{array}{c}9.24 \\
\text { (average) }\end{array}$ & 99.0 & $\begin{array}{ll}\text { - } & \text { Increase } \\
\text { - } & \text { membrane permeability } \\
\text { Reduced salt rejection }\end{array}$ & [112] \\
\hline $\begin{array}{l}\text { Piperazine + triethylamine } \\
\text { + PAMAM/TMC }\end{array}$ & 3.0 & 90.0 & $\begin{array}{ll}- & \text { Flux decline } \\
- & \text { Increase salt rejection } \\
- & \text { Increase hydrophilicity }\end{array}$ & [113] \\
\hline $\begin{array}{l}\text { m-Phenylenediamine } \\
\text { (MPD)/TMC (PAMAM } \\
\text { solution was sprayed } \\
\text { using water as solvent) }\end{array}$ & 20.40 & 98.0 & $\begin{array}{ll}\text { - } & \text { Slightly } \\
\text { smoother surface } \\
\text { - } & \text { Permeability increase } \\
\text { - } & \text { Rejection decrease }\end{array}$ & [114] \\
\hline MPD/TMC/PAMAM & 1.25 & 99.4 & 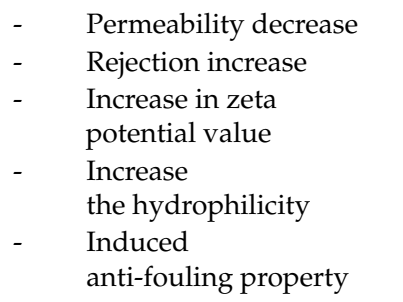 & [83] \\
\hline $\begin{array}{l}\text { PAMAM was added to the } \\
\text { surface of polyvinylidene } \\
\text { fluoride (PVDF) } \\
\text { membrane. }\end{array}$ & 361 & - & $\begin{array}{ll}\text { - } & \text { Increase hydrophilicity } \\
\text { - } & \text { Increase water flux }\end{array}$ & [115] \\
\hline $\begin{array}{c}\text { MPD-acyl } \\
\text { chloride-terminated } \\
\text { hyperbranched polyesters } \\
\text { (HBPAC) @MPD-TMC }\end{array}$ & 3.02 & 98.9 & $\begin{array}{ll}\text { - } & \text { Reduce } \\
\text { - } & \text { surface roughness } \\
& \text { Surface hydrophilicity is } \\
\text { almost same as } \\
\text { - } & \text { Increase flux } \\
\text { - } & \text { Increase salt rejection }\end{array}$ & [116] \\
\hline $\begin{array}{l}\text { Piperazine + poly(ethylene } \\
\text { glycol) + graphene oxide } \\
\text { (GO)/TMC }\end{array}$ & 1.75 & 98.9 & $\begin{array}{ll}- & \text { Increase hydrophilicity } \\
- & \text { Reduced mean pore size } \\
- & \text { of surface and roughness } \\
- & \text { Decrease water flux } \\
- & \text { Increase salt rejection } \\
- & \begin{array}{l}\text { Increase } \\
\text { anti-fouling property }\end{array}\end{array}$ & [117] \\
\hline $\begin{array}{l}\text { Commercial polyamide } \\
\text { thins film composite (TFC) } \\
\text { reverse osmosis (RO) } \\
\text { membrane grafted with } \\
\text { monomethoxy-poly } \\
\text { (ethylene glycol) (MPEG) } \\
\text { brushes }\end{array}$ & 5.78 & 98.6 & $\begin{array}{ll}- & \text { Increase } \\
- & \text { surface roughness } \\
- & \text { Increase hydrophilicity } \\
- & \text { Decrease } \\
- & \text { surface negativity } \\
- & \text { Decline water flux } \\
- & \text { Increase salt rejection }\end{array}$ & [118] \\
\hline
\end{tabular}




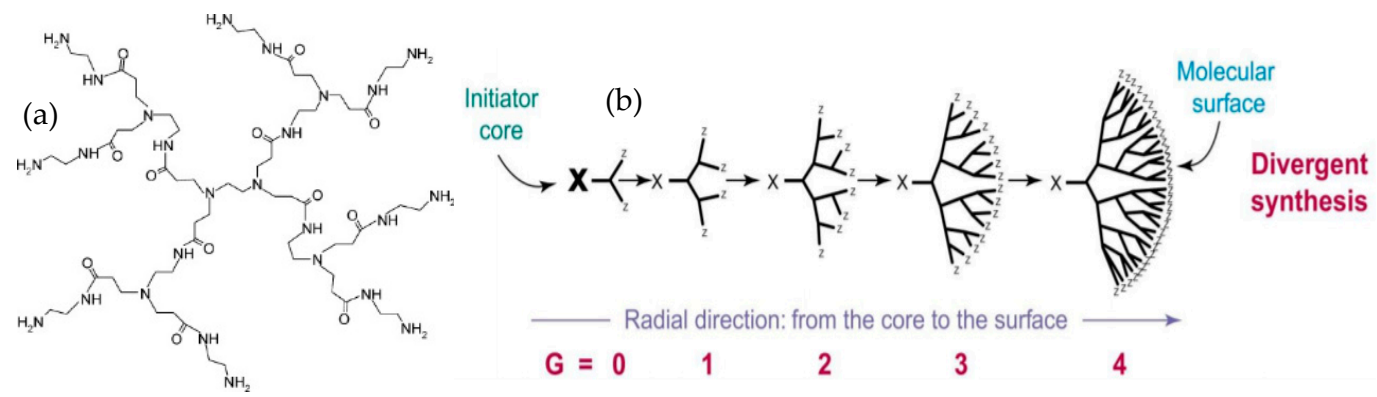

Figure 1. (a) Chemical structure of poly(amidoamine) (PAMAM) of generation 1 (8-NH2 terminal groups), (b) generations 0 to 4 of PAMAM dendrimers; $x$ and $z$ indicate the core and terminal amine functional groups, respectively [108].

PAMAM dendrimers have been used as modified either through direct incorporation or grafting onto the polyamide (PA) matrix due to its high density of reactive terminal amine group. The dendrimer nanotechnology in $\mathrm{RO}$ membrane modification offers new opportunities by providing ability to control the coating nanostructure with easy, versatile control preparation of brush-like surface and crosslinking density of high molecular dendritic molecules. Sarkar et al. have pioneered the research in the application of dendrimers to modify the surface of TFC RO membranes [80]. The membrane has been coated by two approaches namely in-situ crosslinking of PAMAM dendrimers and PAMAM-polyethylene glycol (PAMAM-PEG) multi-arm stars. The coatings were performed through a facile casting technique to form a thin, continuous and even layer that was free from pinholes. They observed that the membranes were more hydrophilic when coated with PAMAM $\left(60^{\circ}\right.$ to $\left.18^{\circ}\right)$ because the presence or lack of free surface amines had little impact on their hydrophilic behavior [80].

Attempts have also been made by introducing different generations of PAMAM dendrimers during the formation of PA layer of TFC membrane. Sum et al. synthesized TFC membranes through interfacial polymerization of mixed amine monomers consisting of piperazine with trimesoyl chloride and PAMAM [112]. As shown in Figure 2, the PAMAM-TMC polymer structure is loosely packed due to the wide dendritic alkyl chain of PAMAM, which prevents close packaging of the polymer chain. Therefore, after piperazine addition into polymer matrix, the void space has been reduced by filling the void by piperazine. Piperazine was used as a void-filler and the addition of piperazine had influence on interfacial polymerisation, resulting in a more compact structured membrane. As a result, $2 \%(w / v)$ piperazine and $0.3 \%(w / v)$ PAMAM were used to improve the permeability of the membrane without substantially affecting the capacity of salt rejection as the rejection was well maintained around $98 \%$ because of the increased free dendrimer volume and the void piperazine filling effect. Mansurpanah et al. have developed and modified a number of polyamide thin layer membranes with difference concentration of PAMAM dendrimer in various generations (G0, G1 and G2). The changes in terms of morphology and separation performance morphology were investigated [113]. They observed that the interfacial polymerization was facilitated with the increasing generations due to the increasing $\mathrm{NH} 2$ functionalities and the reduction in surface tension. As a result, a more compact and thinner layer with reduced porosity was formed. 


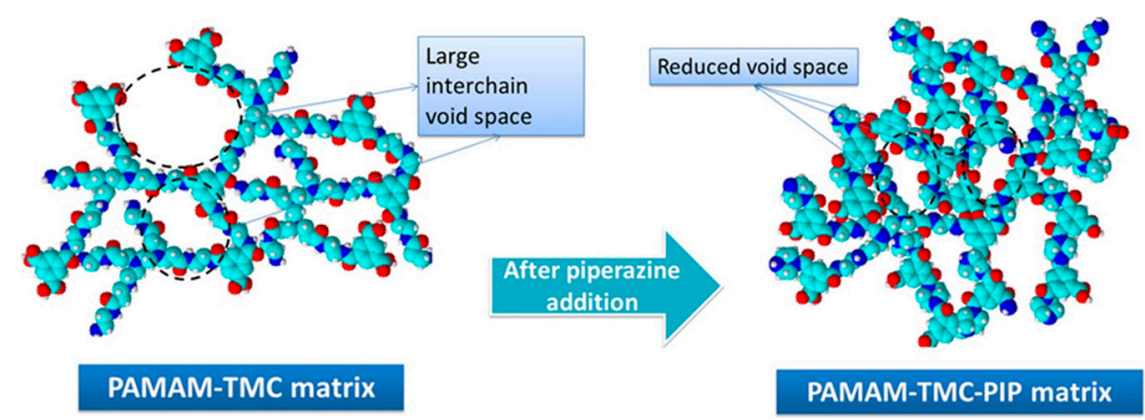

Figure 2. Graphical illustration of space fill models of PAMAM-TMC matrix after addition of piperazine [112].

Recently, Sun et al. prepared PVDF-g-PAA-PAMAM membrane through surface grafting different generations of PAMAM onto membrane [115]. The result indicated that the hydrophilicity of prepared membrane was enhanced whereby pure PVDF membranes, which is $91.2^{\circ}$ after grafting with acrylic acid (AA), reduced to $84.7^{\circ}$ due to presence of carboxyl group in AA and after grafted with PAMAM (PVDF-g-PAA-PAMAM), it decreased significantly to $36.7^{\circ}$ due to amino and amide groups of PAMAM. The heavy metals absorption capacity of PVDF-g-PAA-PAMAM membrane for copper ions were successfully enhanced to $100.98 \mathrm{mg} / \mathrm{g}$ compared to pure membrane which is only $2.6 \mathrm{mg} / \mathrm{g}$. The adsorption power increased after modified with PAMAM due to the amino group coordination with $\mathrm{Cu} 2+$ where the PAMAM molecule inside cavity tend to capture $\mathrm{Cu} 2+$.

The adsorption of heavy metals, $\mathrm{Ni}^{2+}, \mathrm{Pb}^{2+}, \mathrm{Zn}^{2+}, \mathrm{Cu}^{2+}, \mathrm{As}^{5+}$ and $\mathrm{Cd}^{2+}$ by grafting PAMAM dendrimers with different generations on the PES membrane is accomplished, whereby a chemical absorption process is recorded which takes place because of the reaction of complexation [81]. The adsorption capacity of modified membrane with rejection of $99 \%$ against most heavy metals $(\mathrm{Pb} 2+$, $\mathrm{As}^{5+}, \mathrm{Cd}^{2+}$ and $\mathrm{Cu}^{2+}$ ) with excellent pure water permeability which is higher than $3.6 \mathrm{Lm}^{-2} \mathrm{~h}^{-1} \mathrm{bar}^{-1}$ at 10 bars due to increased surface hydrophilicity as high attachment of amine group on membrane surface was observed. In addition, more than $98 \%$ of mixed ions including $\mathrm{Cr}_{2} \mathrm{O}_{7}{ }^{2-}, \mathrm{Ni}^{2+}$, and $\mathrm{Zn}^{2+}$ as well as more than $97.6 \%$ against $\mathrm{As}^{3+}$ have been rejected by H-PAMAM G2 membranes. H-PAMAM G2 membrane shows more stable performance for $72 \mathrm{~h}$ with better anti-fouling property.

Mansourpanah et al. modified poly(piperazineamide) thin layer membranes using polyethylene glycol-modified graphene oxide (PEG/GO) with different concentrations $(0.5,1.0$ and $1.5 \mathrm{wt} \%)$ in aqueous phase [117]. The surface hydrophilicity of L4 membrane (made up of $1.5 \mathrm{wt} \%$ PEG/GO + UV irradiation) was decreased to $18^{\circ}$ compared to other membranes due to presence of hydrophilic functional group. UV radiation likely induced the formation of some surface radicals and the binding of PEG terminal groups with a PA layer, which leads to a longer hydrophilic PEG backbone. Compared to unmodified membrane, the performance of rejection capability against $\mathrm{NaCl}$ and $\mathrm{Na} 2 \mathrm{SO} 4$ of modified membrane, L3 (made up of $1.5 \mathrm{wt} \%$ PEG/GO) was increased to $51 \%$ and $93 \%$ from $18.5 \%$ and $63.5 \%$, respectively, with pure water flux of $14 \mathrm{~L} / \mathrm{m}^{2} \mathrm{~h}$. PEG-modified GO strengthened the physicochemical properties of the thin layer and thus created a highly compact and dense thin layer. The flux recovery ratio (FRR) of modified PEG/GO (L3) membrane was increased significantly from 62 to $90 \%$, and thus had reduced fouling capacity because of hydrophilicity property, small pore size and more compressibility. When the surface was exposed to UV radiation, the pure water flux was enhanced.

Mahdavi et al. reported the modification of cellulose acetate (CA) membrane using two generations of aliphatic hyperbranched polyester ( $\mathrm{Mn}=3370$ and $6620 \mathrm{~g} \mathrm{~mol}^{-1}$ for HBPEG3 and HBPEG4, respectively) as additives [119]. Significantly low water contact angle of $26.7^{\circ}$ was obtained for the CA-HPPEG3 surface, indicating the significant increase in hydrophilicity. This might be associated to the migration in coagulation phase of small and polar HBPEG3 molecules. The smaller molecule of CA-HBPEG3 allowed higher density of hydroxyl group, hence exhibited higher hydraulic resistance than other modified membranes. As a result, CA-HBPEG3 showed improved antifouling property, 
with FRR value and $\mathrm{Rr}$ value of $5 \%$ and 33\%, respectively. In addition, CA-HBPEG3 and CA-HBPEG4 showed significant decrease in adsorbed protein with 1.8 and $2.4 \mu \mathrm{g} / \mathrm{cm}^{2}$, respectively. Water molecules were attracted by the abundant surface hydroxyl group to repel protein molecules. The hyperbranched polyesters enhanced the surface properties while retaining the thermal and mechanical stability through the formation of inter-chain $\mathrm{H}$-bonds.

The active PA layer of a RO-membrane was successfully connected by chemical coupling to a hydrophilic hyperbranched PAMAM [114]. Figure 3a shows the schematic diagram of the modification of the PA layer. During the formation of active layer through interfacial polymerization, PAMAM was added through grafting at the end of residual carbonyl chloride prior to the curing step. As compared to the unmodified membranes, modified membranes cause a substantial increase in water flow due to the inhibition of crosslinking reaction during the last treatment phase. The changes in morphology of unmodified and modified membranes (TFC PAMAM 2) after RO performance test are shown in Figure 3, whereby PA layer is strongly formed after modified with aqueous PAMAM solution due to water is immiscible with hexane. When water was used as solvent, a smooth thin PAMAM film with near complete surface coverage was produced due to the highly hydrophilic PAMAM layer. In Figure $3 \mathrm{c}$ is shown the correlation between protein adsorption and performance parameter (salt rejection and permeability) of the membrane. It was also noticed that, compared to the neat membranes, the modified PAMAM membranes exhibited low protein fouling with high salt rejection, which identified as a hydrogel layer when in contact with water.

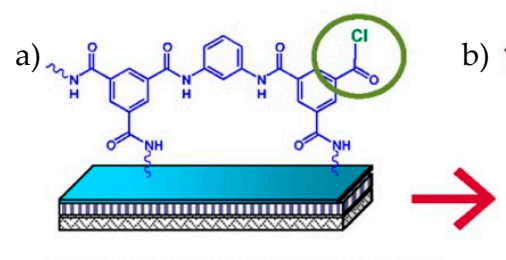

b)
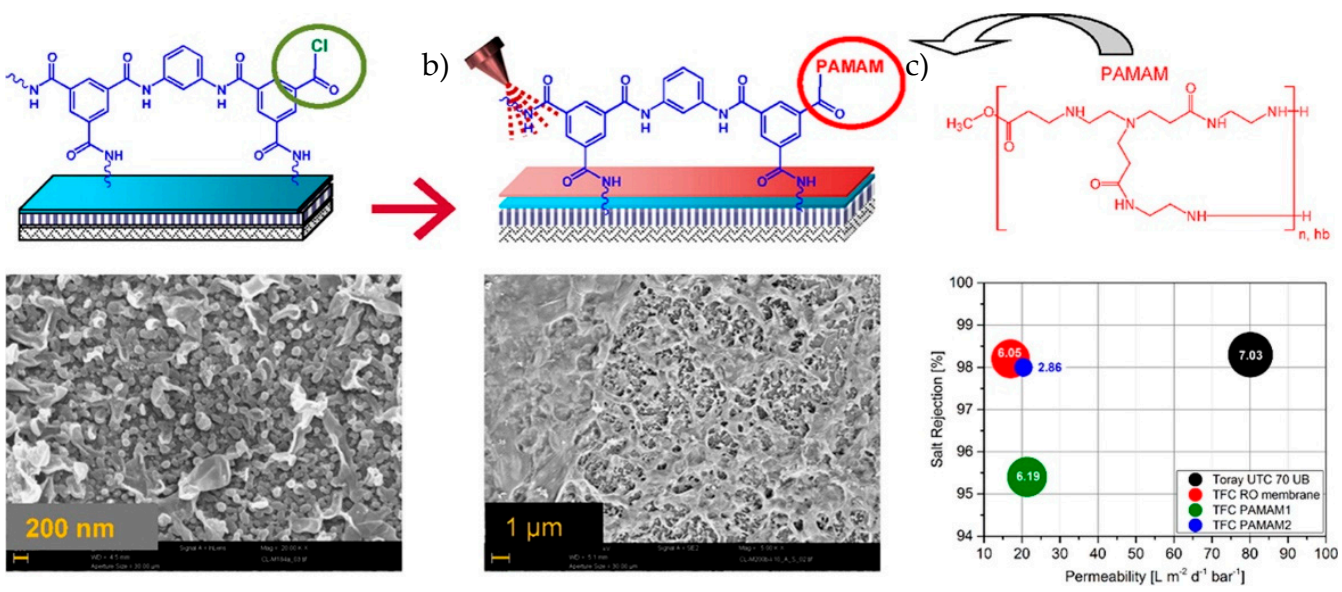

Figure 3. (a) RO membrane modified with hyperbranched polymer (PAMAM) by spraying with different solvent namely water (TFC PAMAM 1) and methanol (TFC PAMAM 2); (b) SEM images of unmodified and modified membrane surface; (c) the correlation between salt rejection, performance parameters permeability, and protein adsorption [114].

In addition, two new types of acyl chloride-terminated hyperbranched polyesters (HBPACs) were synthesized using carboxyl-terminated hyperbranched polyesters (HBPs) with different molecule weights $(\mathrm{Mn} \approx 3289 \mathrm{~g} / \mathrm{mol}$ and $1964 \mathrm{~g} / \mathrm{mol}$ ) (HBPAC-H and HBPAC-L) via acylation reaction with thionyl chloride [116]. The TFC-RO membrane was modified using both HBPAC-H and HBPAC-L by twice-crosslinked interfacial polymerization method exhibited smoother surface and improved surface hydrophilicity. The modified TFC membrane demonstrated 50\% increase in water flux while maintaining high salt rejection of $98.9 \%$. The HBPAC based cross-linked PA layer not only produced thinner PA layer, but also increased the hydrophilic sites of polyamide chains, which in turn helped to rapidly transport water molecules across PA layer and therefore increases water flux. The HBPAC modified membranes showed excellent long-term stability due to good compatibility between polyamide matrix and HBPAC.

Liu et al. (2019) grafted hydrophilic monomethoxy-poly (ethylene glycol) (MPEG) brushes onto the surface of PA TFC RO membrane using glutaraldehyde (GA) as a coupling agent [118]. The modified 
membrane exhibited enhancement of surface hydrophilicity $\left(42.3^{\circ}\right)$ and surface negative charge slightly decreased under neutral condition. With the increased content of MPEG, salt rejection increased from $98.1 \%$ of the pristine membranes to $98.5 \%$ of the PA-GA-MPEG1.0 modified membrane because of the hardening effect of GA on PA layer. The PA-GA-MPEG1.0 membrane improved antifouling property, with a lower FDR value and a higher FRR value compared to that of the pristine membrane. The results showed that the MPEG brush did not only reduce the amount of foulants accumulated on the surface of the membrane, but also facilitated the removal of deposited foulants. During the treatment of secondary textile effluent, the steady-state flux of the modified membrane was increased by $24 \%$ as compared to the pristine membrane and commercial membrane BW30FR. The modified membrane enhanced chlorine membrane stability by reducing $\mathrm{N}$-chlorination sites on the surface of the membrane, as well as improving chemical oxygen demand (COD) removal and rejection.

Bao et al. (2019) fabricated anti-fouling and ammonia-selective TFC-FO membrane by introducing a grafting agent namely generation-2 PAMAM dendrimer to fabricate TFC-FO membranes with different loading of PAMAM as illustrated in Figure 4 [83,120]. After grafting, membrane surface roughness was decreased compared to the neat membranes while the hydrophilicity property was enhanced. The grafted membrane exhibited selectivity towards $\mathrm{NH}_{4}{ }^{+}$that significantly increased ( $98.81 \%$ rejection) compared to the pristine membrane (70.36\% rejection) owing to the presence of surface fixed protonated primary amine. The grafted membranes exhibited good fouling reversibility and fouling resistance by sustaining the average water flux of $29.81 \mathrm{~L} / \mathrm{h} / \mathrm{m}^{2}$ in domestic water. The improvement was due to the creation of a protective hydration layer that able to isolate foulants from the membrane surface.

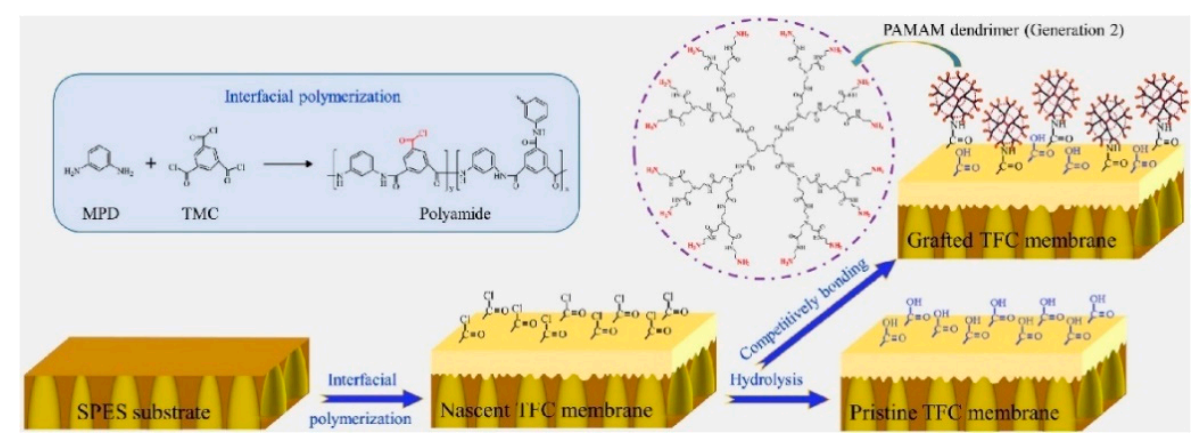

Figure 4. Mechanism of in situ grafting of PAMAM dendrimer on a TFC membrane [120].

As supported by a number of experiments, the use of dendrimers would increase the removal performance of various water pollutants and improve the permeability of membrane. Notwithstanding, there are few concerns need to be considered during the modification process. The synthesis of PAMAM is time consuming due to the repetitive reactions [113]. PAMAM is a water-soluble polymer hence the recyclability of the membrane after the treatment may be limited [115]. The repeated modification may be needed to reintroduce the functionalities to the membranes. The trade-off between rejection and flux is another great concern after modification. For instance, several researchers used HBPs to fabricate new TFC membranes and the flux of these resulting membranes were dramatically increased, but their salt rejection rates were lower than those of commercial membranes due to their large free volume [121].

\subsection{Quaternary Ammonium Compounds (QAC)}

Quaternary ammonium cations, also recognized as quats, are polyatomic ions of the structure $\mathrm{NR}+4$, which are positively charged, and $\mathrm{R}$ is alkyl group or aryl group. QACs are distinguished into three primary groups: (a) linear alkolylammonium; (b) imidazole; and (c) pyridinium compounds, depending on the ternary amine used during synthesis alkylating. This structure allows them to adsorb wastewater sludge, soil and sediments that are mainly negatively charged [122]. The most common 
cationic surfactants currently used in the production of softeners, antistatic ingredients, disinfectants, biocides, detergents, phase transfer agents, as well as many of the products for personal care such as hair treatments, are QAC compounds [122]. The antimicrobial activity of QAC was studied at the beginning of the 1900s. QACs are amphoteric surfactant, playing the dominating role in control of bacterial growth through formation of mixed-micelle aggregates with hydrophobic membrane elements which solubilize the membrane and lysis of the cells. When bacteria come in contact with QAC, the positive QAC group of quaternary ammonium nitrogen can affect bacterial membrane surface charge balance, which causes cells to inactivate and damaged by penetrating into the cell membranes [123]. Mulder et al. (2018) reviewed alkylammonium compounds (QAACs) sequestration mechanisms in soil based on physiochemical properties and the mode of action as antimicrobial agent as schematically displayed in Figure 5 [124]. The positively charged QAACs are sequestrated and enriched into soil, resulting in a reduction in the acute toxicity of free QAC monomers via adsorption on the negatively charged internal and exterior surfaces in claying mineral QAACs. QAACs may also interact with molecules such as lipopolysaccharides or teichoic acids found on the anionic cell wall. Upon their interaction with cell membrane and membrane proteins, QAACs able to dissipate the proton motive strength and finally result in cell leakage and cell death. Table 2 summarizes the antimicrobial activity of different QACs.

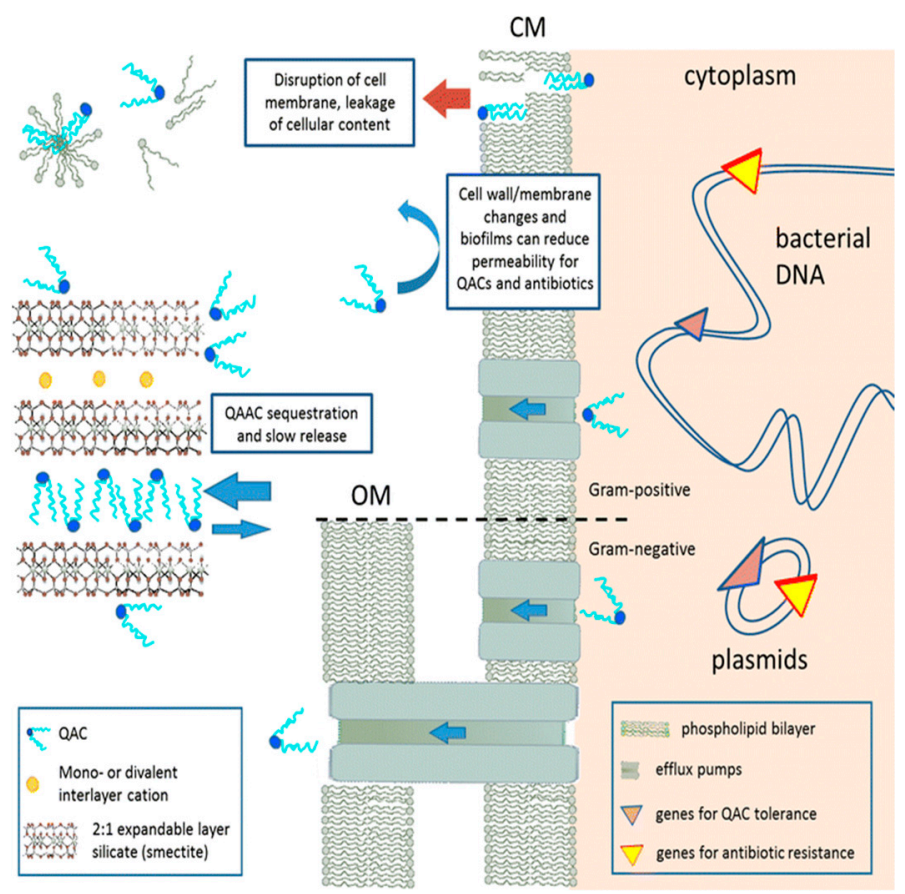

Figure 5. Schematic of the quaternary ammonium compounds (QACs) mode in the presence of soil smectite and tolerance mechanisms. Cytoplasmic membrane (CM) and outer membrane (OM) [124]. 
Table 2. Inhibition rate of bacteria of different quaternary ammonium compounds (QACs) according to the literature.

\begin{tabular}{|c|c|c|c|}
\hline QAC Compounds & Bacteria & Inhibition Rate/Growth Rate & Reference \\
\hline $\begin{array}{l}\text { [2-(Acryloyloxy)ethyl] trimethylammonium chloride } \\
\text { solution (DAC) }\end{array}$ & $\begin{array}{l}\text { E. coli } \\
\text { S. aureus }\end{array}$ & $\begin{array}{l}\sim 98.3 \% \\
\sim 98.5 \%\end{array}$ & [85] \\
\hline $\begin{array}{l}\text { Dimethyloctadecyl[3-(trimethoxysilyl)propyl] } \\
\text { ammoniumchloride (DMOTPAC) }\end{array}$ & $\begin{array}{l}\text { E. coli } \\
\text { S. aureus }\end{array}$ & $\begin{array}{l}\sim 92 \% \\
\sim 93 \%\end{array}$ & [84] \\
\hline Dodecyl dimethyl benzyl ammonium chloride (DDBAC) & $\begin{array}{l}\text { E. coli } \\
\text { S. aureus }\end{array}$ & $\begin{array}{l}0.02 \mu \\
0.02 \mu\end{array}$ & {$[123,125]$} \\
\hline Cetyl trimethyl ammonium bromide (CTAB) & $\begin{array}{l}\text { E. coli } \\
\text { S. aureus }\end{array}$ & $\begin{array}{l}0.0 \mu \\
0.0 \mu\end{array}$ & [126] \\
\hline Cetyltrimethylammonium bromide (CTAB) & $\begin{array}{l}\text { E. coli } \\
\text { S. aureus }\end{array}$ & $\begin{array}{l}99.84 \% \\
100 \%\end{array}$ & [86] \\
\hline $\begin{array}{l}\text { 3-chloro-2-hydroxypropyl trimethyl ammonium chloride } \\
\text { (CHPTAC) }\end{array}$ & $\begin{array}{l}\text { E. coli } \\
\text { S. aureus }\end{array}$ & $\begin{array}{l}89.0 \% \\
76.6 \%\end{array}$ & [127] \\
\hline
\end{tabular}

Cationic cetyl trimethyl ammonium bromide (CTAB) surfactant has been known for its good bactericidal potential. Recently, Cihanoğlu and Altinkaya reported a simple approach of preparing UF membranes with antibacterial properties containing CTAB and polysulfonate polyethersulfone (PSF-SPES) [86]. The CTAB in the gelating medium was allowed to establish electrostatic interaction with the SPES at the polymer/bath interface. The membranes showed excellent antibacterial and antibiofouling properties towards both E.coli and S.aureus due to the presence of functional groups which act as antibacterial agents. Upon dynamic bacterial filtration followed by simple rinsing using phosphate-buffered saline (PBS) solution, the membrane generated at the CMC showed flux recovery of almost $100 \%$. The leaching test showed that nearly $96 \%$ of the CTAB was still retained in the membrane after the period of 30 days.

Ping et al. successfully produced antibiofouling polyvinylidene fluoride (PVDF) membrane using the radical polymerisation electron-transfer-ATRP (ARGET ATRP) method to effectively graft QAC on the membrane [85]. Figure 6 demonstrates a considerable reduction in colony-forming unit (CFU) on QAC-modified (MQ) membranes compared to control membrane (M0) upon the immersion in the bacterial suspensions of E. coli and S. aureus for three hours. The QAC-modified membrane (MQ) showed improved antimicrobial ability with inhibition rates of about $98.3 \%$ for E. coli and $98.5 \%$ for S. aureus through cell integrity destruction. The morphologies of the bacterial cells attached on the MQ and M0 membrane using SEM as shown in Figure 6B-E. This finding shows that nitrogen atom, positively loaded, can damage the bacterial membrane caused by positive binding of QAC head (nitrogen atom) with negatively loaded cell membrane phospholipids that impart antibacterial characteristics to the MQ membrane while the cells adhered to the pristine membrane remained intact.

In another work, Zhang et al. introduced a new approach for the fabrication of antibiofouling membrane. Crosslinking of polydopamine (PDA)/polyethylenimine (PEI) on the membrane surface was first performed, followed by in situ formation of silica nanoparticles layer via silification reaction (MD-Si) and grafting of QAC via alkoxysilane polycondensation reaction (MD-Si-Q) [84]. Through antibacterial activity assessment, they proved that MD-Si-Q membrane exhibited excellent antimicrobial property with high inhibition rate of $\sim 93 \%$ and $\sim 92 \%$ to S. aureus and E. coli, respectively, compared to the M0, MD, MD-Si membranes. The destructive action of positively charged QAC on the negatively charged phospholipids of the bacterial cell membrane disrupted the cellular integrity, causing the cellular content to be released and inactivation of the microorganism. 


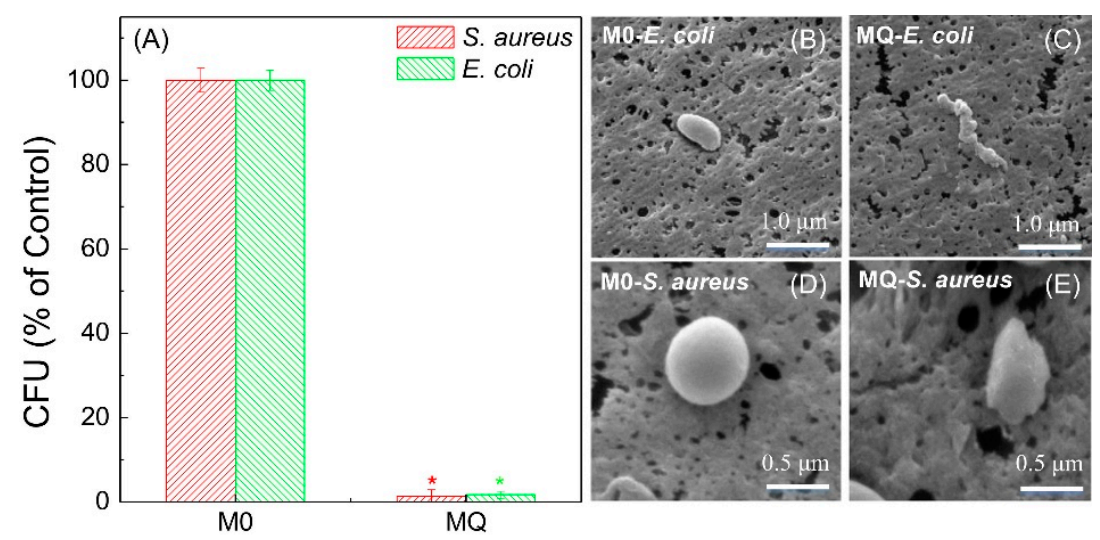

Figure 6. (A) The colony-forming unit (CFU) percentage on the QAC-modified (MQ) membrane in comparison to the unmodified PVDF membrane (M0) $(n=3)$; SEM images showing the morphology of E. coli on the surface of (B) M0 and (C) MQ; S. aureus on the surface of (D) M0 and (E) MQ [85].

Anti-biofouling polyvinylidene fluoride (PVDF) membranes were fabricated by introducing QAC of different loadings into the membrane structure [125]. The anti-fouling study using organic model foulants indicated that the QAC-blended membranes suffered from higher membrane fouling rate towards organic matters due to the thermodynamic effects, based on the Derjaguin-Landau-Verwey-Overbeek (XDLVO) theory. Nevertheless, the membranes modified with QACs exhibited better inhibition capacity towards both model bacteria stains, demonstrating that XDLVO theory is not applicable to biofouling. This is because the antibacterial activities are associated with two steps; 1) the initial contact of bacteria on the surface of modified membranes is governed by XDLVO theory and, 2) after attachment of bacteria, the contact-killing effects induced by QAC would take place to inhibit the bacterial growth as illustrated in Figure 7. This study proved that QAC is an antibacterial agent through contact-killing mechanisms.

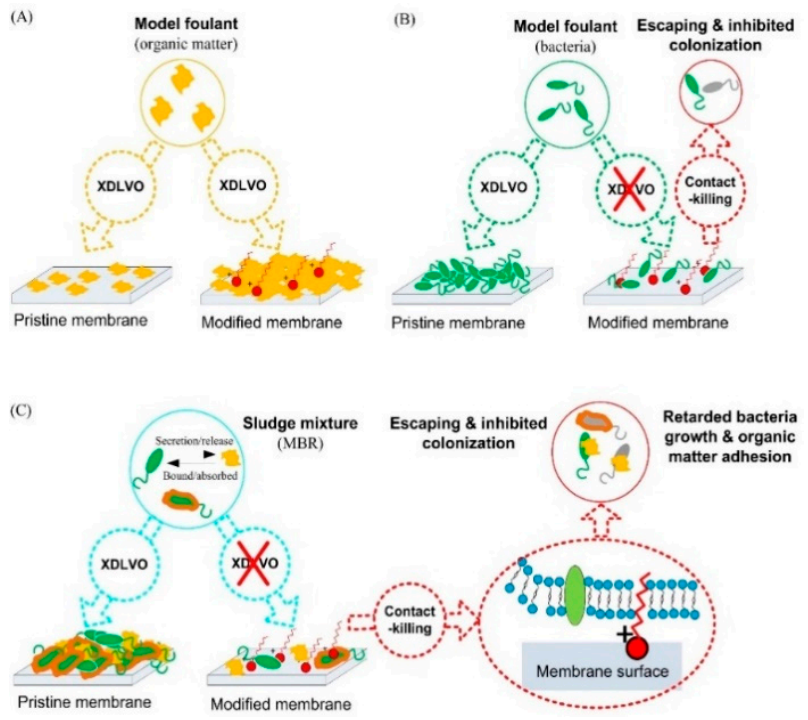

Figure 7. Mechanisms of antimicrobial for both pristine and modified membranes; fouling behaviour of membranes (A) using organic matter as individual model foulants; (B) using bacteria as individual model bio-foulants; (C) using both bacterial and organic foulants in mixed liquor of an membrane bioreactor (MBR) [125].

QAC has been assorted by the electrostatistic interaction on negative and hydrophilic carbon (QAC@Carbon) and these antibacterial agents have been integrated into the matrix of polyvinylidene fluoride (PVDF) via phase inversion method to fabricate microfiltration membranes [126]. Based 
on XPS result, the content of QAC on modified membrane by QAC@Carbon (MCQ) was 2.5 fold of modified by QAC alone (MQ), which is $6.8 \%$. This is because during the membrane forming phase, MCQ demonstrated significant surface segregation relative to MQ membrane. As shown in Figure 8, free QAC molecules migrated towards the membrane surface due to the effects of hydrophobic alkyl chains. As a result, the surface concentration increased upon the drying of the MQ cast film. Due to the hydrophilic carbon content, QAC@Carbon was concentrated on the surface of membrane during the phase inversion process. The introduction of QAC@Carbon into polymeric membrane rendered enhanced antibacterial activities towards both Gram positive and Gram negative bacteria while MCQ membrane had good antibiofouling behaviors in cross-flow filtration compared to MQ.

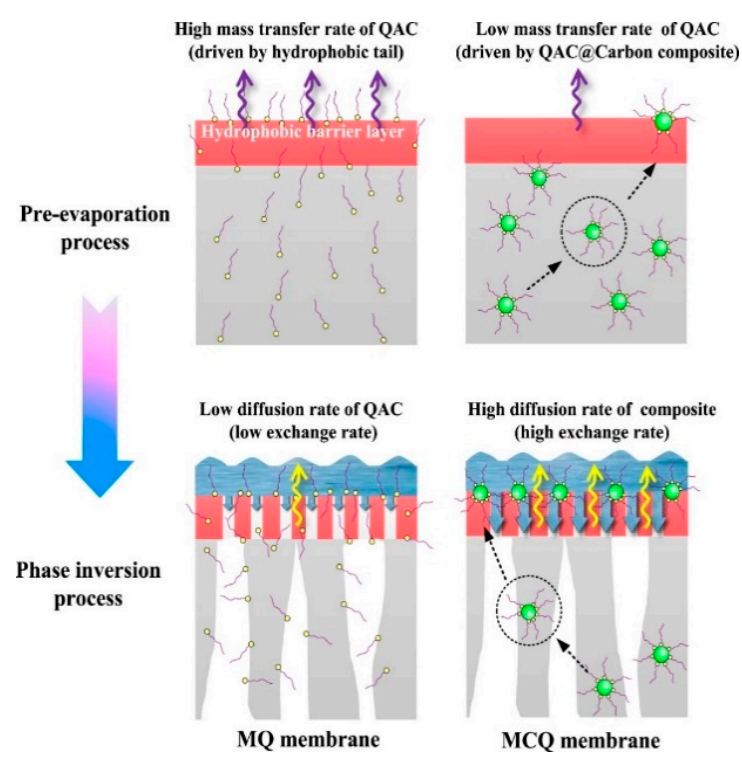

Figure 8. The effect of carbon carrier on QAC segregation toward membrane surface for both pre-evaporation and phase inversion process [126].

The surface of cellulose triacetate RO membranes has successfully been altered with 3-chloro-2-hydroxypropyl ammonium chloride (CHPTAC), prepared by immersion precipitation technique, using saponification and etherification method under various underlying conditions [127]. Quaternized CTA-RO membranes demonstrated increased surface roughness and irrugularity. Although the membrane structures were retained, the modification have contributed to higher hydrophilicity. Antibacterial activity against E. coli and S. aureus was demonstrated where the QCTA-RO membranes showed bactericidal rate of 78.7-89.0\% for E. coli and $64.4-76.6 \%$ for S. aureus. Therefore, the longer the modification time, the more quaternary ammonium groups were added on the membrane surface resulting in a higher bactericidal rate. Meanwhile the permeation flux increased slightly compared to the CTA-RO membrane, with their salt rejections reaching $92 \%$.

In general, QACs is a stable non leaching antibacterial compound in which can be covalently bonded with the surface of the membranes through various interactions such as esterification between epoxy group and hydroxyl group. QACs is antibacterial agents based on contact killing hence it establishes a stable and long-lasting antibiofouling properties compared to release killing concept [86]. The advantages of contact killing compared with the release killing is that the latter often result in a significant loss of antibacterial activity and cause an environmental risk [85].

\subsection{Polyzwitterions}

Zwitterions, also known as dipole ion, is a special class of macromolecules that have same number of anions and cations on their polymer chain, which make stronger and more stable electrostatic bonds with water than hydrophilic materials [128]. Common cations zwitterion is quaternized ammonium 
while anions zwitterions are sulfobetaine (SB), carboxybetaine (CB), phosphorylcholine (PC) [129]. Because of super hydrophilic property in the presence of abundant ions and strong hydration layer, outstanding fouling resistance and biocompatibility, zwitterions have received great attention in recent decades [130-132]. Zwitterions have both negative and positive charge units. Through electrostatic interactions, stronger and more stable hydration layers are created $[89,133]$. In general, zwitterionic polymers are endowed with excellent water binding capability that not only facilitates the water transport across the membrane, but also enhances its fouling resistance [88].

Recently, Sun et al. successfully fabricated an antifouling membrane by incorporating zwitterionic polyethylene glycol (SZ-PEG) into PVDF through surface segregation as illustrated in Figure 9A [134]. As shown in Figure 9B, the FTIR spectrum has confirmed the formation of the SZ-PEG polymers through the peaks associated to the stretch vibration of sulfonic acid group at 1030 and $1100 \mathrm{~cm}^{-1}$. The $1 \mathrm{H}$ NMR spectrum in Figure $9 \mathrm{C}$ indicates the presence of catechol groups. Sun et al. observed that the SZ-PEG was evenly distributed throughout the membrane matrix. The decreased thermodynamic strength of casting solutions increased the pore size and enhanced the surface roughness of the modified membranes. Notably, the catechol groups oriented on the surface of the membrane increased the surface hydrophilicity hence increased the FRR to $96.9 \%$ while achieving high bovine serum albumin (BSA) rejection of $93.8 \%$. The water flux was also increased by $423 \%$ compared to the PVDF pristine membrane.

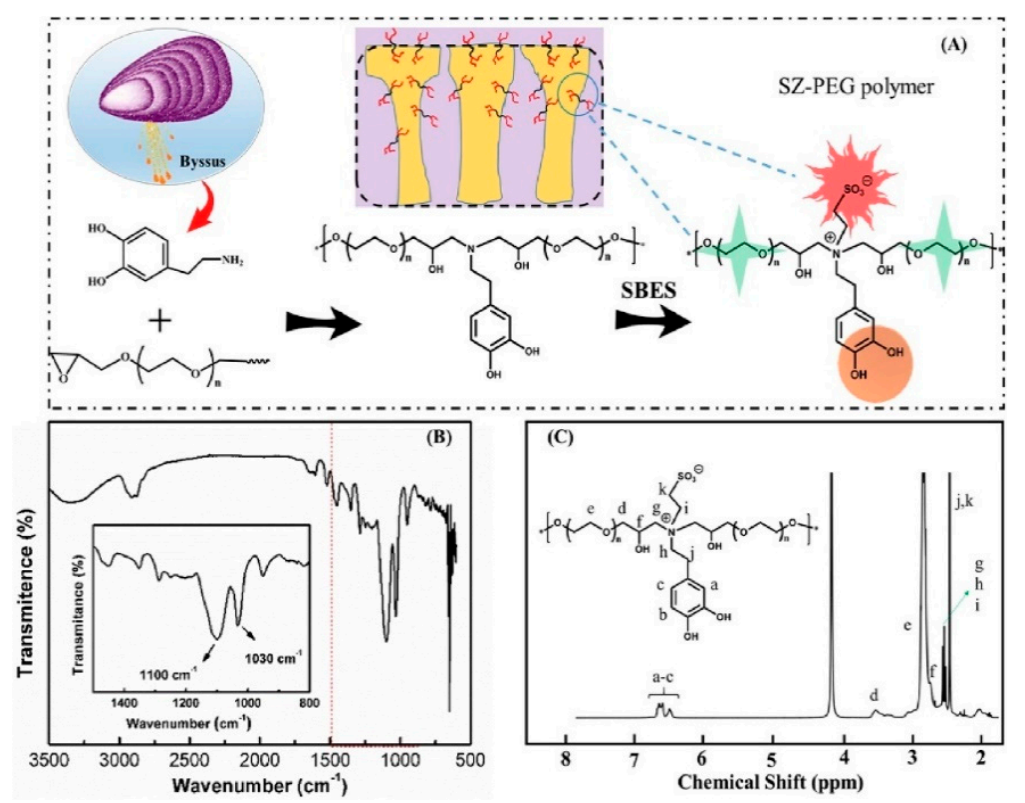

Figure 9. (A) Schematic illustration of the formation of SZ-PEG polymer. (B) FTIR spectrum and (C) H NMR spectrum of SZ-PEG polymer [134].

Kirschner et al. successfully incorporated poly(2-methacryloyloxyethyl phosphorylcholine) (PMPC), a polymer zwitterion into polydopamine (PD) coatings on polysulfone membranes for oil-water separations using a one-step solution coating process [135]. In comparison to the unmodified membranes, both modified membranes (PD-PMPC and PD modified membranes) were charcterized with significantly improved hydrophilicity. The increased fouling resistance observed in the PD-PMPC modified membranes was attributed to the increased surface hydrophilicity.

Ji et al. proposed a one-stop route which involved simple process and mild condition to synthesize of zwitterionic dopamine nanoparticles (ADNP) using an oxidative polymerization process with the zwitterionic amine and dopamine molecules, followed by the interfacial cross-linking on porous supporting layer as shown in Figure 10 [34]. The good interaction between zwitterionic dopamine and polymeric matrix was established through the covalent and non-covalent interactions. 
The resulting ADNP TFN membranes exhibited excellent hydrophilicity with a significant decrease in the contact angle to $\sim 10^{\circ}$ when the ADNP content was increased from $0 \%$ to $0.5 \% w / v$. Due to the compatibility of ADNP and polymer matrix, as well as the creation of appropriate interfacial channels, the water flux of TFNM-ADNP membranes increased significantly from 22.8 to $144.8 \mathrm{~m}^{-2} \mathrm{~h}^{-1}$ for neat and modified membranes, respectively. In addition, the TFN membranes based on zwitterionic dopamine nanoparticles demonstrated improved resistance towards polysaccharide, humic acid and protein fouling.

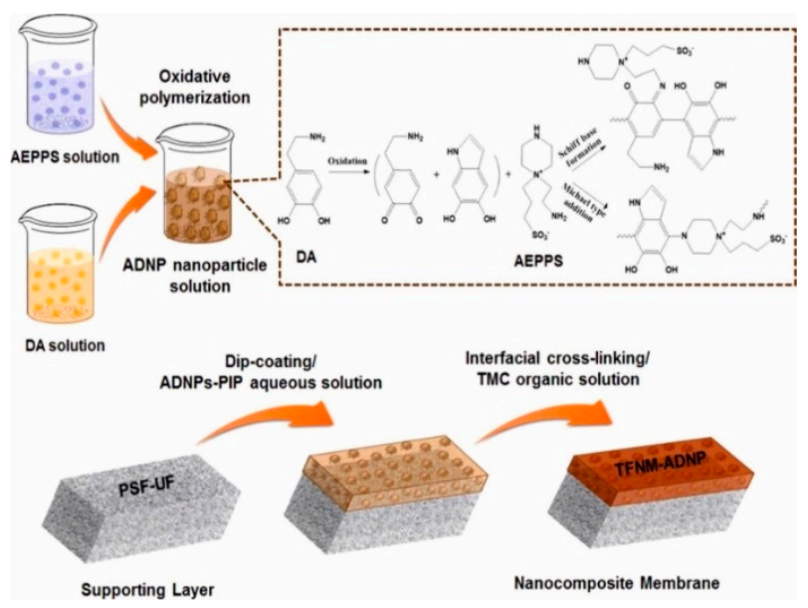

Figure 10. Schematic diagram for preparation of ADNP nanoparticles (top panel) and ADNP thin-film nanocomposite membranes (TFNM-ADNPs, bottom panel) [34].

Ji et al. fabricated NF membrane containing zwitterionic polyelectrolyte nanoparticles (ZPNPs) [136]. The ZPNPs particle was prepared by the ionic crosslinking between zwitterionic copolymers and sodium carboxymethyl cellulose. The TFN membranes incorporated ZPNP showed greater hydrophilicity which could be attributed to the fast water transport across membranedue to the attraction of water molecules towads the sulfobetaine groups. The di/monovalent salt separation performance was significantly improved in which the ZPNP modified TFN membrane demonstrated increased water permeability of $109.7 \mathrm{~L} \cdot \mathrm{m}^{-2} \cdot \mathrm{h}^{-1} \cdot \mathrm{MPa}^{-1}$. The $\mathrm{NaCl}$ and $\mathrm{Na}_{2} \mathrm{SO}_{4}$ rejection was enhanced by $191 \%$ and $125 \%$, respectively, compared to the pristine TFC.

A significant amount of work has been done by using zwitterions for membranes surface modification to enhance or improve anti fouling performance. Meng et al. grafted salt-responsive zwitterionic polymer, poly (4-(2-sulfoethyl)-1-(4-vinylbenzyl) pyridinium betaine) (PSVBP) onto a commercial TFC RO membrane through redox initiated graft polymerization [131]. Through crossflow protein test of about $100 \mathrm{~h}$ duration, the polyamide-grafted-PSVBP (PA-g-PSVBP) membrane demonstrated excellent antifouling with easy cleaning properties. Figure 11a shows that the permeation flux significantly declined for the first $10 \mathrm{~h}$ for both commercial TFC RO membranes (XLE) and PA-g-PSVBP membranes, after which the membrane flux reached a plateau and slowly decreased throughout the $60 \mathrm{~h}$ of filtration. The BSA surface interactions influenced the adsorption of BSA on the membrane surface during the first stages of fouling. But as the fouling progressed, BSA-BSA interactions become more dominant at the membrane surface. These interactions strongly depend on the surface characteristics of the membrane. After cleaning with DI water, the flux of the PA-g-PSVBP membrane increased by $90 \%$, but no obvious change was made in the flux of the XLE membrane (Figure 11b). This is due to the nature of zwitterionic brush which act as a protein repellent. 
a

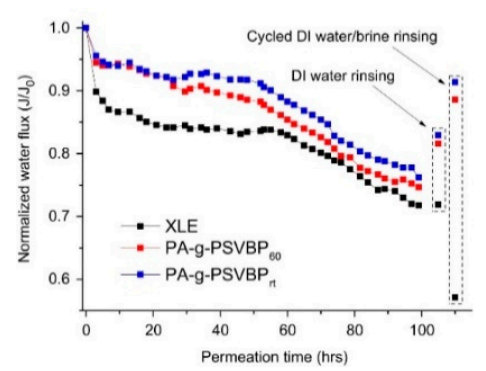

b

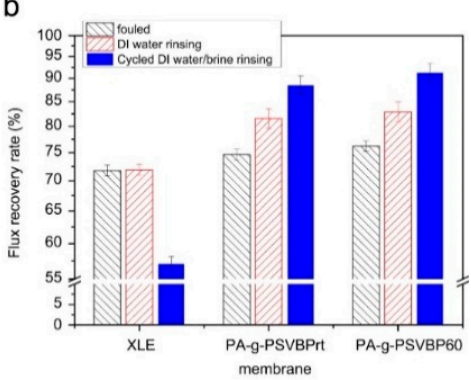

Figure 11. (a) Normalized water flux and (b) flux recovery rate of commercial TFC RO membranes (XLE), PA-g-PSVBP60 and PA-g-PSVBP rt [131].

You et al. successfully applied surface-initiated graft polymerization technique to prepare a series of stimuli-responsive RO membrane. Three types of stimuli-responsive polymers, i.e., salt-responsive sulfobetaine methacrylate (SBMA) and 4-(2-Sulfoethyl)-1-(4-vinyl-benzyl) pyridinium betain (SVBP) as well as temperature responsive $\mathrm{N}$-isopropylacrylamide (NIPAM) were grafted onto the surface RO membrane [137]. The modification resulted in increased surface negative charges, smoother and highly hydrophilic surfaces. These physiochemical properties enhanced fouling resitance and facilitated facile cleaning by controling the concentration of salt and the temperature of the feed solution.

Zwitterionic diamine monomer $\mathrm{N}$-aminoethyl piperazine propane sulfonate (AEPPS) has been introduced into m-phenylenediamine (MPD) aqueous solution to synthesis zwitterionic thin film composite reverse osmosis membrane (TFCMZs) [138]. The water flux of TFCMZs enhanced from $29.9 \mathrm{~L} \cdot \mathrm{m}^{-2} \cdot \mathrm{h}^{-1}$ to $54.5 \mathrm{~L} \cdot \mathrm{m}^{-2} \cdot \mathrm{h}^{-1}$ with the increase of AEPPS content from 0 to $10 \%$, whereas the salt rejection remains stable above $98 \%$ due to the membrane surface having more affinity to water molecules. Moreover, the desalination performance of TFCMZs remained stable during the 28 day testing period due to the occurrence of ionic interactions between zwitterionic groups, which are favourable to stability. In addition, the TFCMZs demonstrated excellent fouling resistance and easy cleaning properties with the use of tannic acid (TA) and sodium alginate (NaAlg) as model foulants.

Zwitterionic sulfobetaine methacrylate (SBMA) polymers have been grafted onto hydrophobic PVDF membranes with the intention of improving treatment of different oil emulsions via membrane distillation (MD) (both without and with different surfactants) [87]. The water contact angle of low concentration of SBMA-2 wt \% grafting decreased dramatically to $45^{\circ}$ compared to pristine membrane $\left(110^{\circ}\right)$. Meanwhile, with increasing contents of SBMA, the PVDF membrane become increasingly oleophobic. The MD performance in terms of flux and conductance enhanced further with increased SBMA grafting at high concentrations in 2000 ppm of two non-surfactant oil emulsions (i.e., hexadecane and soybean oil). The trend of fouling and wetting were more extreme than hexadecane for soybean oil. The electrostatic interactions alone could not justify this phenomenon by quantifying zeta potential values. The results of this study showed that the zwitterionic polymers grafting has anti-fouling and anti-wetting properties, particularly for feeds containing oil emulsions of MD.

In general, zwitterion material produces a strong dipole moment due to the opposite charges, allowing a good interaction between substrate and PA layer, surface fouling in the TFC membrane has also been reduced. However, the modification of TFC membrane using zwitterion does not always lead to desired performance enhancement. In a recent study by Zhai et al. who modified PVDF membranes with zwiterrion polymers, it was found that the fouling resistance towards BSA was not improved due to the nature of the fouling behavior [139]. The fouling behavior was influenced by the interaction between the foulants instead of the membrane surface characteristics. Such observation indicated that systematic analysis is still required to further understand the fouling mechanisms prior to the design of membrane surface. 


\subsection{Chitosan, CS}

$\mathrm{CS}[(\mathrm{C} 6 \mathrm{H} 11 \mathrm{NO} 4) \mathrm{n}]$ is a linear polysaccharide that contains active hydroxyl and amino groups produced from $\mathrm{N}$-deacetylation of chitin obtained from insects, shells of shrimp, crabs and other crustaceans [140]. Based on past research, CS is not only biocompatible, biodegradable, and nontoxic nature but it also exhibits many biological-activities such as antioxidant, hypocholesterolemic, antimicrobial, immune-stimulating, and anti-inflammatory activities where significant attention has been given to wide range of industrial applications in the food, pharmaceutical, agricultural, biomedical and environmental industries [141,142]. CS also exhibits outstanding water permeability, good film forming ability and high hydrophilicity due to rich in oxygen functional group $[90,143]$. CS is extensively applied in membrane fabrication due to its high film-forming ability, robustness and chemical resistance. Table 3 summarizes the separation and permeability of the modified membranes.

Table 3. Separation and permeability performance of membranes.

\begin{tabular}{|c|c|c|c|c|}
\hline Membrane & Fabrication Method & $\begin{array}{c}\text { Water } \\
\text { Permeability }\end{array}$ & Salt Rejection (\%) & Reference \\
\hline $\begin{array}{l}\text { Polyacrylonitrile (PAN)/cellulose acetate } \\
\text { (CS)-3.5 }\end{array}$ & Hydrolyzation & $3.98 \mathrm{~L} / \mathrm{m} 2 \mathrm{~h}$ bar & 97.0 & 90 \\
\hline Zeolitic imidazolate framework (ZIF)-8/CS & Dip coating & $7.2 \mathrm{~kg} / \mathrm{m} 2 \mathrm{~h}$ & $>99.5$ & 91 \\
\hline PVDF/CS & Blend & $631.4 \mathrm{~L} / \mathrm{m} 2 \mathrm{~h}$ bar & - & 92 \\
\hline Cellulose acetate/CS & Embedding & $3.09 \mathrm{~L} / \mathrm{m} 2 \mathrm{~h}$ bar & 91.0 & 146 \\
\hline CS/GO nanocomposite & Immersion (layer by layer) & $2.95 \mathrm{~L} / \mathrm{m} 2 \mathrm{~h}$ bar & 91.11 & 147 \\
\hline $\mathrm{CS} / \mathrm{TFC}(\mathrm{NaOH}$ treatment) & Immersion & $2.12 \mathrm{~L} / \mathrm{m} 2 \mathrm{~h}$ bar & 94.52 & 148 \\
\hline
\end{tabular}

CS acts as a chelating agent with heavy and transition metals via chemical bonds as it is hydrophilic in nature. Ekambaram et al. prepared PVDF membrane matrix by incorporating carboxymethyl CS-Zinc oxide bionanocomposite via phase inversion method [144]. The result indicates that modified membranes exhibited better hydrophilicity and lower surface roughness compared to pure membrane. Modified membrane had high salt rejection compared to unmodifed membrane, the order as: $\mathrm{Na}_{2} \mathrm{SO}_{4}$ $>\mathrm{MgSO}_{4}>\mathrm{NaCl}>\mathrm{MgCl}_{2}>\mathrm{LiCl}$. The fouling was optimally reduced when the concentration of nanocomposition on the membrane surface was increased, using humic acid as a model foulant due to deacreased pore sizes and increased skin layer thickness. Additionally, the modified membranes provided better mechanical and thermal stability and strong resistance over two repeated cycles.

Elizalde et al. modified hydrophobic PVDF membranes by blending a series of CS into polymer matrix via phase inversion method [92]. Blending CS to PVDF led to a more open membrane structure that resulted in greater membrane porosity of and pore size due to the higher thermodynamic instability of blend dope solutions. The water contact angle of modified CS-membranes had decreased to $115^{\circ}$ compared to pristine membrane. Microfiltration experiments with BSA water feed solution showed both increased flux as well as decreased fouling of PVDF/CS blend membranes in comparison with pristine membrane. Nevertheless, CS-concentrated membranes above $1 \%$ showed surface ruptures after filtration tests. This phenomenon caused swelling, which resulted in high water uptake by CS particles. Thus, understanding the impact of CS on the manufactured membranes may make fine tuning of membrane properties more effective.

Shi et al. successfully fabricated composite structure as a support layer by embedding thin CS sub layer onto polyacrylonitrile (PAN) nanofiber mat (PAN/CS) composite FO membrane via hydrolysis method as illustrated in Figure 12 [90]. Chitosan play an important role whereby it filled the porous surface and increased interfacial force between PAN nanofiber mat and active layer and contact area. Results showed that PAN/CS composite membrane reached the tensile strength above $30 \mathrm{MPa}$ and Young's modulus reached above $90 \mathrm{MPa}$, which is higher compared to previous studies of nanofiber-based and phrase-inversion FO substrates due to excellent crystallinity and dense molecular 
structure of CS. The composite FO membrane of $3.5 \%$ of CS concentration had high water flux and reverse salt flux.

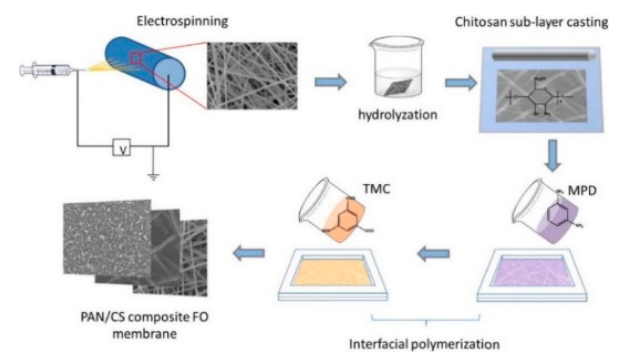

Figure 12. Schematic illustration of the preparation of PAN/CS composite forward osmosis (FO) membrane [90].

Ghaemi et al. successfully prepared FO membranes by embedding CS nanoparticles synthesized via ionic gelation method into the matrix of CA membrane [145]. The surface hydrophilicity and porosity of nanocomposite membranes increased substantially as compared to the pure CA-membrane due to presence of hydrophilic CS and structural parameter has significantly reduced by $0.30-1.3 \mathrm{~mm}$. In both the FO and PR mode, the composite membranes provided high water flux and low reverse salt flux compared to an unmodified membrane, so that FO water permeation across the membrane formed by the optimum chitosan nanopolymer increases approximately four times over CA. In addition, nanocomposite membranes' reverse salt flux decreased up to $0.05 \mathrm{gMH}$ and the FO efficiency of the membrane, which is evaluated by desalination of seawater, resulted in an acceptable performance. It can be inferred that, due to improvement of structural characteristics and improvement of FO water permeation and reverse salt flow, the use of nanopolymers chitosan as an additive for the modification of forward osmosis CA membrane has great potential for water desalination.

Salehi et al. developed a novel highly effective FO membrane via layer-by-layer (LbL) assembly on porous supportive layer, using positive-CS and negative-graphene oxide (GO) nanosheets [146]. The supporting layer was prepared using a wet phase inverse method by blending hydrophilic SPES in PES matrix. The LbL membranes had considerably higher values of water flux, which were $2-4$ orders of magnitude higher compared to the TFC with a small compromise on the salt permeability. By using 200 ppm of sodium alginate as a foulant model, the LbL membrane showed better fouling resistance than the TFC due to abundance of hydrophilic functional groups of GO and CS. The interaction of positively charged CS chains and GO nanosheets through the formation of amide bond enhanced the membrane's mechanical stability for long operation.

CS were incorporated into the selective layer of FO membrane via in-situ interfacial polymerization reaction on the surface of sulfonated SPES-PES support layer [147]. The result showed a strong trade-off between water permeability and salt rejection of various CS modified membranes. The membranes incorporated with high concentration of CS displayed lower flux but higher salt rejections. The hydrophilic surface facilitated water permeation across the membrane. In addition, the thickness of the final thin active layer increased significantly with the increasing CS concentration. Thus, the thicker active layer can serve as a barrier film to prevent the increased water permeation.

Kebria et al. prepared TFN membrane by coating zeolitic imidazolate framework (ZIF-8)/CS on the PVDF membrane surface for air gap membrane distillation (AGMD) [91]. The TFC membrane showed a stable and increased water flow by $350 \%$ compared to the unmodified PVDF membrane. In addition, of ZIF-8/CS modified membrane had superior salt rejection over $99.5 \%$ due to higher surface porosity and lower mean surface pore size (Figure 13). The TFN membrane showed excellent antifouling property in which the flux reduction was merely $16 \%$ while flux recovery was $90 \%$. 

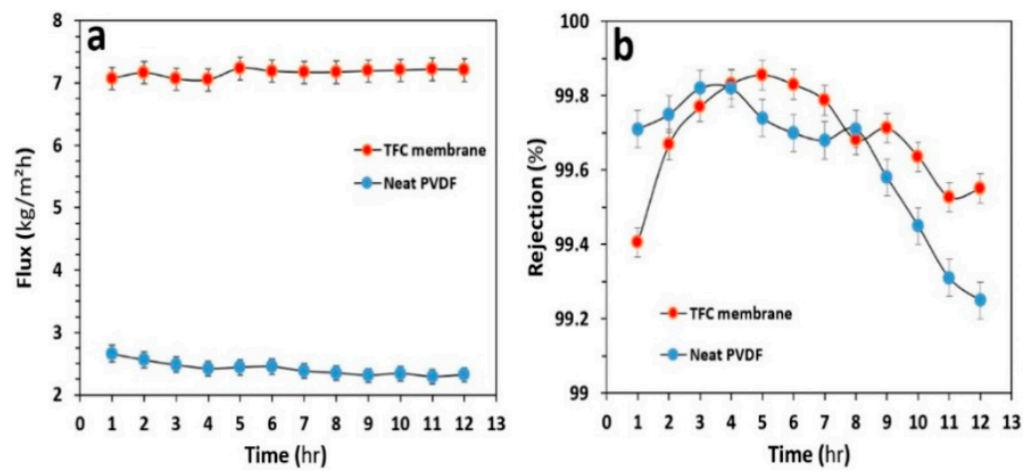

Figure 13. (a) Water flux, (b) salt rejection of TFC membrane and neat PVDF during air gap membrane distillation (AGMD) test [91].

In general, CS contains abundant functional oxygen groups that give water molecules a high degree of hydrophilicity to capture and facilitate water transport. One major concern when applying CS as a modifier for membrane is the leaching of this antimicrobial agent when subjected to higher operating pressures. Apart from deteriorating the antimicrobial efficacy, the formation of defective sites on the membrane is also detrimental to the membrane separation performance. The solubility of CS is another drawback. CS is typically solubilized in acetic acid, but does not well dissolve in organic solvents, this had limited the usage of CS in membrane preparation which normally involves the dissolution of polymer pellets in organic solvent [92,144].

\subsection{Cellulose}

Cellulose is a linear chain and a non-branched polysaccharide that is composed of two anhydroglucose rings $\left(\mathrm{C}_{6} \mathrm{H}_{10} \mathrm{O}_{5}\right) \mathrm{n}$ connected by an oxygen bound covalently to one glucose ring $\mathrm{C} 1$ and $\mathrm{C} 4$ of adjoining ring (1-4 linkage), known as the $\beta 1-4$ glucosidic bond ( $\mathrm{n}$ is repeat units per chain) [148-150]. Cellulose is a biopolymer resource obtained from plant sources and is used in many applications such as textile, water-treatment, packaging, biomedicine, and optical/electrical devices [151]. Cellulose has attracted great attention from researchers due to its unique properties including renewability, availability, non-toxicity, cost-effectiveness, environment-friendly attributes, biocompatibility, biodegradability, thermal and chemical stability, derivatizabilty and easy for chemical modification for the desired quality, which allows the filtration process to act as potential applicant for oil/water emulsion [148,152-156]. Nanocellulose interest has recently increased significantly because of its unique chemical and physical properties; the molecular chain formation has a relatively high persistence length and tight packaging by multiple hydrogen bonds with arrangement in microfibrils or bundles of polysaccharide that are arranged in fibrils (bundles of microfibrils) $[148,157,158]$. In general, there are two types of nanocellulose; (i) cellulose nanocrystals (CNC) obtained by acid treatment and (ii) cellulose nanofibrils (CNF) produced mainly through mechanical disintegration [110]. Many researchers focused on improvement of CA properties, such as mechanical strength and thermal stability for water treatment applications.

Recently, Moeinzadeh et al. synthesized anti-fouling UF membrane by incorporating different amount of amino-functionalized nanocrystalline cellulose (NCs) [94]. The characterization showed that the total membrane porosity and hydrophilicity were substantially improved upon the addition of NCs. The modified membrane incorporated with $1 \mathrm{wt} \% \mathrm{NCs}$ nanocomposite achieved optimum water flux and outstanding oil rejection, which were approximately $43 \%\left(105.2 \mathrm{~L} / \mathrm{m}^{2} \cdot \mathrm{h}\right)$ and $10 \%(>98.2 \%)$, respectively, higher than that of pristine membrane. This can be attributed to the reduced membrane surface pore size which has improved the retention of oil particles. In addition, nanocomposite membrane exhibited good water flux recovery rate after one and four cycles with $\sim 98 \%$ and $\sim 85 \%$, respectively, during $250 \mathrm{ppm}$ oil-in-water emulsion solution. The role of NCs in membrane is more 
important due to existence of hydrophilic functional groups $(-\mathrm{OH})$ which makes the membrane an anti-fouling membrane during oil-in-water emulsion treatment.

Zhang et al. successfully incorporated different amount of CN into PES UF membranes [159]. The hydrophilicity of the PES/CNC membrane was improved with the increasing CNC content. With increased CNC concentrations up to $1.0 \mathrm{wt} \%$, the pure water flux was enhanced from 92 to 195 LMH. By adding $5.0 \mathrm{wt} \%$ of CNC into the PES, mixed matrix membrane with reduced pore size and thicker selective layer was formed, hence improving the BSA rejection from 93 to $97 \%$. The membrane exhibited subtantial improvements in the biofouling resistance towards gram positive $S$. aureus bacteria, as evidenced from the apparent halo zone around the membranes after conditioning with polyhydroxyamines (PAH).

A carboxymethyl cellulose-graft-poly(acrylic acid)/bentonite nanocomposite membrane was synthesized in the presence of silica gel as an adsorbent of cationic dye (CV) and metal (Cd (II)) ions from aqueous solution [160]. The membranes showed a proportional relationship to their bentonite content with the dye and metal adsorption capacity. Using the M10 sample (in an optimized condition), maximal adsorption of ion CV and Cd (II) were found to be 546 and $781 \mathrm{mg} \mathrm{g}^{-1}$, respectively. The adsorption kinetics could be described using pseudo-second-order model and Freundlich isotherm model. Thermodynamic studies indicated a spontaneous and thermodynamically favorable adsorption mechanism for endotherms.

Few studies on the application of natural cellulose in oil-water separation have been reported. Wang et al. [93] successfully electrospun hydrophobic-oleophilic nanofibrous PVDF membranes incorporated with CNC. The PVDF membranes incorporated with CNC shown high flux and separation efficiency in the separation of gravity-driven surfactant-stabilized water-in-toluene and water-in-bean oil emulsions.

Sobolčiak et al. also electrospun co-polyamide 6,12 (coPA) nanofibers modified by CNC through using date palm leaves [161]. With CNC concentration up to $1 \mathrm{wt} \%$, the mechanical properties of the membrane were significantly improved in which the Young modules increased by $224 \%$. The modified membranes were proven to have a great efficiency in oil-to-water separation and membrane efficiency, particularly with the increasing CNC content. The membrane incorporated with $5 \mathrm{wt} \%$ of CNC demonstrated separation efficiency greater than $98 \%$.

Liu et al. reported an easy and effective method to incorporate 2,2,6,6-tetramethylpiperidine-1-oxyl radical (TEMPO)-oxidized CNFs into the polyamide layer of TFC RO membrane during interfacial polymerization in order to increase membrane efficiency [161]. With the increased loading of CNFs from 0 to $0.2 \%$, the CNF-TFC membranes exhibited good permeability in which the contact angle of RO membrane was decreased from 31.2 to $17.8^{\circ}$ because of hydroxyl functional group of CNFs. In addition, the water flux of the membrane was improved by more than 50 to $29.8 \mathrm{~L} \cdot \mathrm{m}^{-2} \cdot \mathrm{h}^{-1}$ whereas $\mathrm{NaCI}$ rejections increased from 94.0 to $95.6 \%$ at the loading of $0.02 \mathrm{wt} \%$ of CNs of nanocomposite membrane compared to bare TFC membrane. The results of the chlorine stability test showed good chlorine resistance performance than pristine TFC membranes.

TFN membrane was synthesized by embedding CNCs into the selective layer of TFN through interfacial polymerization [95]. The CNC loading of $0.1 \%$, the permeate flux during brackish water desalination was doubled from 30 to $63 \mathrm{~L} / \mathrm{m}^{2} \cdot \mathrm{h}$ with negligible effect on the salt rejection $(97.8 \%)$. Besides improving the hydrophilicity, the presence of $\mathrm{CNC}$ also resulted in greater surface roughness in which the number of protuberances were helpful to increase the effective surface area for water transport. The modified membrane exhibited $11 \%$ lesser water flux reduction compared to the unmodified counterpart using feed solution containing $300 \mathrm{ppm}$ of BSA. The enhanced antifouling properties was attributed to the combined effects of improved surface hydrophilicity and surface negative charge upon the addition of CNC.

The uniform and homogeneous dispersion within polymer matrices is still one of the major challenges faced in the development of cellulose-modified membrane. Surface modification of cellulose has become more common to address the dispersion and also to introduce additional surface functionality to the nanomaterial. Jonoobi et al. modified the surface of CNC using 
(3-aminopropyl) triethoxysilane (APTES) to introduce more active sites for the adsorption of pollutants in wastewater [162]. Besides the anioic charge original presented on the CNC surface due to the sulfate ester groups, the modification using APTES also favourably introduced cationic groups to further enhance the adsorption of dye pollutants with opposite charges. It should also be pointed out that, although the adsorptive capability of CNC is an attractive feature for pollutant removal from wastewater, the saturation and recovery of the $\mathrm{CNC}$ in the nanocomposite membranes is a great challenge to be addressed. Additionally, microfibrillated celluloses (MFCs) and CNCs may still be too costly to be practically applied for membrane modification as they are normally synthesized through energy intensive and less efficient methods such as high pressure homography and acidic hydrolysis [161]. As economics is one of the utmost important consideration for industrial application, more focus should be placed in the exploration of synthesis method that is more facile and less expensive.

\subsection{Polydopamine, $P D A$}

PDA is a bio-inspired polymer that has similar characteristic as adhesive secretions of mussels and is able to adhere to marine substrates for long periods and adhere onto nearly all types of organic and inorganic surfaces without surface modification [163]. PDA, also known as robust 'bio-glue' polymer involving the simple single-step surface functionalization method, was first reported in 2007 [164]. The adhesive mechanisms of PDA have been reported by Lee et al. [165]. PDA formed by self-polymerization in weak alkaline solution with presence of oxygen using low concentrations of dopamine [166]. The polymerized PDA retains its role as reactive macromolecules due to active functional group (hydroxyl, amine, catechol and imine) for functionalization and further modification for various application purpose [167]. There are two key features that attracted PDA for achieving strong adhesion; (i) high catechol (3,4-dihydroxybenzene) content due to the presence of 3,4-dihydroxy-Lphenylalanine (DOPA), (ii) high primary and secondary amine content due to lysine (Lys) and histidine residues $[168,169]$. The coexistence of catechol and amine functional group correlate to interfacial adhesion to create conformal coating on different surface in ambient conditions [170]. The catechol groups in DOPA would be interacted with substances via hydrogen bonds, electrostatic interactions, covalent interaction, hydrophobic interaction and coordination [171]. PDA has emerged as outstanding surface modification tool due to the unique properties such as self-polymerization, high anchoring capability, and special ability to improve the surface hydrophilicity by forming a very thin layer on substrate surface, thereby improving the antifouling properties.

Tripathi et al. reported a facile approach to fabricate antifouling membrane through PDA coating on PSF microporous membrane [167]. N,N-dimethylethylenediamine (DMDA) with tertiary amine functionality was further functionalized on the membrane. Both PDA coating and functionalization improved hydrophilicity by introducing abudant hydrophilic functional groups such as phenolic hydroxyl on the surfaces which could form strong bonding with water molecules. The modified membrane showed lower protein adsorption due to the increased hydrophilicity. Compared to pristine PSF, the modified membranes exhibited significantly increases in flux recovery (94\% of FRR) which indicate good antifouling property. Thus, the ultra-low fouling membranes showed applicability for multi cycle operation in separation and filtration applications.

The surface modification of polyarylene sulfide sulfone (PSS) membrane using PDA has been reported by Xiong et al. [172]. Althought the addition of PDA favouarably increased the hydrophilic properties of the membrane, exessive amount of PDA could block the membrane pores, hence reducing the membrane flux. With $2 \mathrm{~g} / \mathrm{L}$ of PDA, the modified membrane exhibited enhanced flux up to 134.6 $\mathrm{L} / \mathrm{m}^{2} \mathrm{~h}$ and the flux remained almost constant within $96 \mathrm{~h}$ operation. Kasemset et al. who modified PSf UF membranes with PDA also observed the reduction of membrane pore size upon the addition of excessive PDA hence reducing the flux [173]. These observations suggested that the loading of PDA should be carefully optimized so that the desired properties are not compromised.

Ji et al. successfully deposited PDA on a porous PVDF support and then catecholamine in PDA was cross-linked with TMC through interfacial polymerization by varying the some important 
parameters such as dopamine concentration, TMC concentration and crosslinking time [174]. The PDA deposited, PVDF membrane exhibited enhanced hydrophilicity due to the presence of hydroxyl groups. At the optimum conditions, the modified membrane exhibited permeation flux of $2411 \pm 33 \mathrm{~g} \cdot \mathrm{m}^{-2} \cdot \mathrm{h}^{-1}$ and $11001 \pm 989 \mathrm{~g} \cdot \mathrm{m}^{-2} \cdot \mathrm{h}^{-1}$ for feed temperature of $25^{\circ} \mathrm{C}$ and $70{ }^{\circ} \mathrm{C}$, respectively. This comparison indicates that PDAA-S membrane is stable under high feed temperature during long-term operation.

An anion exchange membrane (AEM) has been prepared by modification of electrodeposition of GO and PDA coating [175]. The GO@PDA modified AEM (GO@PDA-M) demonstrated improved surface hydrophilicity and surface negative charge owing to the hydrolysis of phenolic hydroxyl group. The GO@PDA-modified AEM demonstrated considerable anti-fouling ability without affecting the desalination efficiency. The rejection of GO@PDA-M increased by 39.3\% compared to pristine membrane in the presence of $150 \mathrm{mg} / \mathrm{L}$ sodium dodecyl benzene sulfonate (SDBS). The anti-fouling property was maintained for long-term operation.

Wang et al. prepared PDA modified membrane using fast PDA coating (fPDAc) strategy by introducing sodium periodate(NaIO4) to speed up the deposition process [176]. compared to the sPDAc method, quartz crystal microbalance measurements (QCM-D) showed a significantly higher rate of deposition of PDA and mass deposition rate of PDA by fPDAc method, resulting in a $97 \%$ reduction in the coating time, reaching an area mass of $2000 \mathrm{ng} / \mathrm{cm}^{2}$. The higher coating rate was due to the oxidative property of $\mathrm{NaIO} 4$ which accelerated the self-assembly and covalent bond-forming reactions. Both sPDAc and fPDAc methods improved the surface hydrophilicity and reduced the membrane surface charge due to the presence of PDA. Although both coated membranes had reduced pure water flux, fPDAc coated membrane was less affected at a real mass deposition of approximately $1000 \mathrm{ng} / \mathrm{cm}^{2}$ due to partial hydrolysis of amide bond under NaIO4. Moreover, both sPDAc and fPDAc-coated membrane showed significantly higher $\mathrm{NaCI}$ rejection of above $93 \%$ compared to pristine membrane. fPDAc coated membrane had comparatively better $\mathrm{NaCI}$ rejection because of increased charge density in the PA rejection layer. These coated membranes also showed better antifouling property for oil/water or wastewater applications.

Recently, Kwon et al. prepared TFC-FO membrane by using aromatic solvent-based interfacial polymerization method using PDA-modified PE (DPE) support [177]. The hydrophobic pristine PE support uniformly hydrophilized the PDA coating and serve beneficial structural features such as extremely thin $(\sim 8 \mu \mathrm{m})$ and highly porous and interconnected pore structure to enable the long-term operational stability. Furthermore, the interfacial polymerization involving toluene solvent allowed the formation of highly selective polyamide layer on the hydrophilic DPE support. In comparison with commercial and other lab-scale membrane, the prepared DPE-TFC membrane showed remarkably higher FO water flux ( $\sim 4.5$ times higher) with $\sim 63 \%$ lower specific salt flux. In addition, the DPE-TFC membrane demonstrated high durability for long lasting operation in harsh environments.

In general, by strong covalent and non-covalent interactions to the substrate, the PDA layer adheres tightly to the surface and gives a very stable PDA coating. However, PDA is an amphoteric substrate and negatively charged only if the $\mathrm{pH}$ is greater than four. In comparison, an efficient PDA modifier layer normally takes a long time (24 h) [175]. Nonetheless, the use of PDA coating on porous membranes will mitigate severe reductions in membrane pure water permeability to prevent the increase in local permeate flux, either regional or overall, due to pores being narrowed or blocked as a consequence of the modification of PDA which could worsen the fouling [173].

\section{Future Perspective and Concluding Remarks}

Membrane-based filtration has been commonly used for the treatment of sewage and brackish water, pure water and waste water, as well as for the isolation and purification of substances in industrial applications. It has become one of the key innovations for tackling global water shortage and pollution. Due to its good separation efficiency, remarkable advances were made in membrane preparation and implementation; scientists have continued to test state-of-the-art, high-permeability and high-selectivity of membranes, and have found structural stable and fouling resistant and further 
reduce their use of energy and operating costs. The sustaining of this research would help improve productivity and protect the membranes for long-term use. Sustainable, low cost, maintenance and reuse of nanocomposite membranes are the main concerns in membrane technology and crucial for global prosperity, health and security.

The design of multifunctional membranes with exceptional anti fouling and antimicrobial properties may require revolutionary surface engineering and production methods to make next generation developments in membrane technology. As summarized in Table 4, in recent years there have been considerable advances in modification of polymer-matrix membranes using macromolecules for water treatment. The integration of macromolecules not only change the physiochemical properties of membranes (hydrophilicity, porosity, charge density, thermal and mechanical stability), but also give membranes some unique properties based on macromolecules architecture (i.e., linear, crosslinked, branched) and could induce new characteristics and functions based on its synergetic effects. This offers a new dimension for the design and development of the next generation of high-performance polymer membranes.

Several challenges still need to be addressed to optimize the design of the organic composite membranes for practical applications at the large scale. First, various development methods are currently limited to scientific research by reasons of high costs, difficult operation and scalability and only a small number of methods are ready for commercial use. For example, the fabrication cost of nanocrystal such as zeolite nanocrystal and $\mathrm{CNC}$ are high. Besides, during regeneration the cellulose degradation causes irreversible damage, loss of its high crystallinity, mechanical strength and high resistance to organic solvents, acids and base materials.

Second, the process of preparation requires complex multiple steps and involve the use of chemicals, needed special instruments and time consuming, which restricts their application. Very stable polymers are difficult to dissolve to form casting solution as no crosslinking is available. For instance, polyether ether ketone (PEEK) is stable in most organic solvent, thus sulfuric and methanesulfonic acid is used to prepare casting solution. The acid used in the solution indicates high hazard to people working in the membrane fabrication process and environmental impact when neutralized prior to disposal. The surface modification techniques such as self-assembly monolayers (SAMs), layer-by-layer (LBL) film deposition, chemical conjugation and plasma treatment is time consuming and involved multiple deposition steps using interacting polymer and their quality highly depends on specific surface properties.

Third, in most cases the use of these modified membranes requires high stability for long term operation. The covalently interaction between membrane and modifiers would make chemical grafting more desirable as compared with the physical surface coating. Moreover, few researches have concentrated on surface modifier stability during cleaning. Indeed, cleaning is a necessary process in RO process. In practical applications, the acidified, alkaline, or other cleaning environments can result in the degradation of the modifier. Although fouling may not be completely avoided for anti-fouling RO membranes, a lot of research and development are still required in order to develop improved RO membranes for long-term and commercial use. 
Table 4. Application of representative macromolecules for the modification of polymeric membranes for water treatment.

\begin{tabular}{|c|c|c|c|c|c|c|}
\hline \multicolumn{2}{|c|}{ Macromolecules } & Membrane Process & Applications & Polymers & Filler Concentration & \\
\hline \multirow{9}{*}{ Dendrimers } & \multirow{5}{*}{ PAMAM } & \multirow[t]{2}{*}{ NF } & $\begin{array}{l}\text { Evaluation of antifouling properties and removal of } \\
\text { salts (NaCl, Na2SO4). } \\
\text { Model foulant: BSA }\end{array}$ & \multirow{3}{*}{ PES } & \multirow[t]{2}{*}{$0.5,1.5$, and $3 \mathrm{wt} \%$} & Reterence \\
\hline & & & $\begin{array}{l}\text { Removal of heavy metals such as } \mathrm{Pb} 2+, \mathrm{Cu} 2+ \\
\mathrm{Ni2} 2+, \mathrm{Cd} 2+, \mathrm{Zn} 2+\text { and As5 }+\end{array}$ & & & [81] \\
\hline & & $\mathrm{RO}$ & $\begin{array}{l}\text { Evaluation of antifouling properties and protein } \\
\text { adsorption } \\
\text { Model foulant: BSA }\end{array}$ & & $10 \% w / v$ & [114] \\
\hline & & FO & $\begin{array}{l}\text { Evaluation of ammonia-selective and anti-fouling } \\
\text { capacities for domestic wastewater treatment }\end{array}$ & SPES & $\begin{array}{l}0.1 \mathrm{wt} \%, 0.5 \mathrm{wt} \%, \\
1 \mathrm{wt} \% \text { and } 2 \mathrm{wt} \%\end{array}$ & [120] \\
\hline & & UF & Removal of copper ions & PVDF & $3 \mathrm{wt} \%$ & [115] \\
\hline & Polvesters & $\mathrm{RO}$ & Desalination: Salt removal $(\mathrm{NaCl})$ & PSF & $\begin{array}{l}0.005 \mathrm{wt} \% \text { and } \\
0.01 \mathrm{wt} \%\end{array}$ & [116] \\
\hline & Polyesters & NF & $\begin{array}{l}\text { Evaluation of antifouling properties } \\
\text { Model foulant: BSA }\end{array}$ & CA & $2.5,5.0,7.5$ and $10 \mathrm{wt} \%$ & [119] \\
\hline & & $\mathrm{NF}$ & Desalination: Salt removal ( $\mathrm{NaCl}$ and $\mathrm{Na} 2 \mathrm{SO} 4)$ & PEG & $0.5,1.0$ and $1.5 \mathrm{wt} \%$ & [117] \\
\hline & Polyethylene glycol & $\mathrm{RO}$ & $\begin{array}{l}\text { Evaluation of antifouling property and durability } \\
\text { against chlorine } \\
\text { Desalination: Salt removal }(\mathrm{NaCl})\end{array}$ & PA & $\begin{array}{l}0.5,1.0,1.5 \text { and } \\
2.0 \mathrm{wt} \%\end{array}$ & [118] \\
\hline & $\begin{array}{l}{[2 \text {-(Acryloyloxy)ethyl] }} \\
\text { trimethylammonium chloride } \\
\text { solution (DAC) }\end{array}$ & & $\begin{array}{l}\text { Evaluation of antibacterial property for } \\
\text { water/wastewater treatment } \\
\text { Model bacteria: E.coli or S. aureus }\end{array}$ & & $28 \mathrm{mmol}$ & [85] \\
\hline Quaternary & $\begin{array}{l}\text { Dimethyloctadecyl[3- } \\
\text { (trimethoxysilyl)propyl] } \\
\text { ammoniumchloride } \\
\text { (DMOTPAC) }\end{array}$ & MF & $\begin{array}{l}\text { Evaluation of antibacterial property for } \\
\text { water/wastewater treatment } \\
\text { Model bacteria: E. coli or S. aureus }\end{array}$ & PVDF & $15 \mathrm{~mL}$ & [84] \\
\hline $\begin{array}{l}\text { Ammonium } \\
\text { Compounds (QAC) }\end{array}$ & $\begin{array}{l}\text { Dodecyl dimethyl benzyl } \\
\text { ammonium chloride (DDBAC) }\end{array}$ & & $\begin{array}{l}\text { Evaluation of antifouling and antibacterial property } \\
\text { for water/wastewater treatment. } \\
\text { Model foulant: BSA and SA } \\
\text { Model bacteria: E. coli or S. aureus }\end{array}$ & & $0.1,0.2$ and $0.4 \mathrm{wt} \%$ & [125] \\
\hline & $\begin{array}{l}\text { Cetyl trimethyl ammonium } \\
\text { bromide (CTAB) }\end{array}$ & UF & $\begin{array}{l}\text { Evaluation of antibacterial property for } \\
\text { water/wastewater treatment } \\
\text { Model bacteria: E. coli or S. aureus }\end{array}$ & PSF-SPES & $0.4 \mathrm{wt} \%$ & [126] \\
\hline & $\begin{array}{l}\text { 3-chloro-2-hydroxypropyl } \\
\text { trimethyl ammonium chloride } \\
\text { (CHPTAC) }\end{array}$ & $\mathrm{RO}$ & $\begin{array}{l}\text { Evaluation of antibacterial properties and removal } \\
\text { of salt (NaCl). } \\
\text { Model bacteria: E. coli, S. aureus }\end{array}$ & CTA & $0.06 \mathrm{~mol} \mathrm{~L}^{-1}$ & [127] \\
\hline
\end{tabular}


Table 4. Cont

\begin{tabular}{|c|c|c|c|c|c|c|}
\hline \multicolumn{2}{|c|}{ Macromolecules } & Membrane Process & Applications & Polymers & Filler Concentration & \multirow{2}{*}{$\begin{array}{c}\text { Reference } \\
{[131]}\end{array}$} \\
\hline \multirow{8}{*}{ Polyzwitterions } & $\begin{array}{l}\text { poly } \\
\text { (4-(2-sulfoethyl)-1-(4-vinylbenzyl) } \\
\text { pyridinium betaine) (PSVBP) }\end{array}$ & \multirow{2}{*}{ 19 } & $\begin{array}{l}\text { Evaluation of antifouling properties and removal of } \\
\text { salt (NaCl). } \\
\text { Mixture model: BSA }\end{array}$ & \multirow[b]{2}{*}{ PA } & $2 \mathrm{mmol} \mathrm{L}^{-1}$ & \\
\hline & $\begin{array}{l}\text { poly (sulfobetaine methacrylate) } \\
\text { (PSBMA), poly } \\
\text { (4-(2-Sulfoethyl)-1-(4-vinyl- } \\
\text { benzyl) pyridinium betain) } \\
\text { (PSVBP) and poly } \\
\text { (N-isopropylacrylamide) } \\
\text { (PNIPAM) }\end{array}$ & & $\begin{array}{l}\text { Evaluating of antifouling and easy-cleaning } \\
\text { properties. } \\
\text { Model foulants: BSA and } \mathrm{CaCO} 3\end{array}$ & & $4 \mathrm{mmol} \mathrm{L}^{-1}$ & [137] \\
\hline & N-aminoethyl piperazine & UF & $\begin{array}{l}\text { Evaluation of antifouling properties and removal of } \\
\text { salt (NaCl and Na2SO4). } \\
\text { Model foulants: BSA, SA or HA }\end{array}$ & PSF & $\begin{array}{l}2.0,10.0,20.0 \\
\mathrm{mg} \cdot \mathrm{mL}^{-1}\end{array}$ & [34] \\
\hline & propane sulfonate (AEPPS) & RO & $\begin{array}{l}\text { Evaluation of antifouling properties and removal of } \\
\text { salt (NaCI) for water treatment } \\
\text { Model foulants: TA and NaAlg }\end{array}$ & & $\begin{array}{l}0 \%, 5 \%, 10 \%, 25 \% \text { and } \\
50 \% \text { in aqueous } \\
\text { solution. }\end{array}$ & [138] \\
\hline & $\begin{array}{l}\text { Catechol-functionalized } \\
\text { zwitterionic PEG }\end{array}$ & UF & $\begin{array}{l}\text { Evaluation of antifouling property and removal of } \\
\text { BSA for water treatment. }\end{array}$ & PVDF & $0.5,1.0,1.5 \mathrm{wt} \%$ & [134] \\
\hline & $\begin{array}{l}\text { 3-dimethyl } \\
\text { (methacryloyloxyethyl) } \\
\text { ammonium propane sulfonate } \\
\text { (DMAPS) }\end{array}$ & NF & $\begin{array}{l}\text { Evaluation of antifouling properties and removal of } \\
\text { salt (NaCl/Na2SO4) } \\
\text { Model foulants: BSA }\end{array}$ & PSF & 35,55 , and $75 \mathrm{wt} \%$ & [136] \\
\hline & $\begin{array}{l}\text { 2-(Methacryloyloxy) ethyl } \\
\text { dimethyl } \\
\text { (3-sulfopropyl)-ammonium } \\
\text { hydroxide }\end{array}$ & MD & $\begin{array}{l}\text { Evaluation of anti-fouling and anti-wetting of oil } \\
\text { emulsions. } \\
\text { Model foulant: hexadecane emulsion and soy bean } \\
\text { oil emulsion }\end{array}$ & PVDF & $2,5,10 \mathrm{wt} \%$ & [87] \\
\hline & $\begin{array}{l}\text { Poly(2-methacryloyloxyethyl } \\
\text { phosphorylcholine) (PMPC) }\end{array}$ & UF & $\begin{array}{l}\text { Evaluation of antifouling properties for oil-water } \\
\text { separations. } \\
\text { Model foulants: soybean oil emulsion }\end{array}$ & PSF & $2 \mathrm{~g} / \mathrm{L}$ & [135] \\
\hline & & & Desalination and water treatment & PAN & $\begin{array}{l}2 \%, 2.5 \%, 3 \%, 3.5 \% \\
4 \%, 4.5 \% \text { and } 5 \%(\mathrm{wt})\end{array}$ & [90] \\
\hline & Chitosan & $\mathrm{FO}$ & Water desalination & $\mathrm{CA}$ & $\begin{array}{l}0.2,0.8,1.6,3.2 \text { and } \\
4.8 \mathrm{wt} \%\end{array}$ & [145] \\
\hline & & & $\begin{array}{l}\text { Evaluation of antifouling properties removal of salt } \\
\text { (Na2SO4) } \\
\text { Model foulants: SA }\end{array}$ & SPES-PES & $0.1 \mathrm{wt} \%$ & [146] \\
\hline & & & Desalination: Salt removal ( $\mathrm{NaCl}$ and $\mathrm{Na} 2 \mathrm{SO} 4)$ & PA & $0.5,1.0$, and $2.0 \mathrm{wt} \%$. & [147] \\
\hline
\end{tabular}


Table 4. Cont

\begin{tabular}{|c|c|c|c|c|c|c|}
\hline & acromolecules & Membrane Process & $\begin{array}{c}\text { Applications } \\
\end{array}$ & Polymers & Filler Concentration & Reference \\
\hline \multirow{3}{*}{\multicolumn{2}{|c|}{ Chitosan }} & MD & $\begin{array}{l}\text { Evaluation of antifouling properties and removal of } \\
\text { salt }(\mathrm{NaCl})\end{array}$ & \multirow{3}{*}{ PVDF } & $0.5 \mathrm{~g}$ & [91] \\
\hline & & MF & $\begin{array}{l}\text { Evaluation of antifouling properties for water } \\
\text { treatment } \\
\text { Model foulants: BSA }\end{array}$ & & $\begin{array}{l}0.5,1.0,1.5,2.0 \text { and } \\
2.5 \%(w / w)\end{array}$ & [92] \\
\hline & & NF & $\begin{array}{l}\text { Removal of inorganic salts and humic acid and } \\
\text { evaluation of antifouling } \\
\text { Inorganic salts: } \mathrm{Na} 2 \mathrm{SO} 4, \mathrm{MgSO} 4, \mathrm{NaCl}, \mathrm{MgCl} 2 \text {, } \\
\mathrm{LiCl}\end{array}$ & & $0.05,0.15$ and $0.2 \mathrm{wt} \%$ & [144] \\
\hline \multirow{7}{*}{ Cellulose } & \multirow{5}{*}{ Nanocrystalline cellulose (NCs) } & \multirow[t]{2}{*}{$\mathrm{UF}$} & $\begin{array}{l}\text { Evaluation of antifouling resistance against oil } \\
\text { molecules deposition for wastewater treatment }\end{array}$ & PSF & $0.5,1.0$, and $2.0 \mathrm{wt} \%$ & [94] \\
\hline & & & $\begin{array}{l}\text { Evaluation of antifouling and antibacterial property } \\
\text { for water treatment. } \\
\text { Model foulant: BSA } \\
\text { Model bacteria: E. coli and S. aureus }\end{array}$ & PES & $\begin{array}{l}0.02,0.08,0.15 \text { and } \\
0.75 \mathrm{wt} \%\end{array}$ & [159] \\
\hline & & RO & $\begin{array}{l}\text { Evaluation of antifouling properties and removal of } \\
\text { salt (NaCl) } \\
\text { Model foulant: BSA }\end{array}$ & PSF & $0.05 \%, 0.1 \%, 0.2 \% w / v$ & [95] \\
\hline & & \multirow[t]{2}{*}{ MF } & $\begin{array}{l}\text { Separation of water-in-oil emulsions } \\
\text { (soya-bean oil) }\end{array}$ & PVDF & 2,4 or $6 \mathrm{wt} \%$ & [93] \\
\hline & & & $\begin{array}{l}\text { Separation of water-in-oil emulsions for wastewater } \\
\text { treatment } \\
\text { (vegetable oil and diesel oil) }\end{array}$ & PA & $\begin{array}{l}0.2,0.5,1.0,2.5,5.0 \\
\text { wt } \%\end{array}$ & [160] \\
\hline & cellulose nanofibers (CNFs) & $\mathrm{RO}$ & $\begin{array}{l}\text { Evaluation of antifouling properties and chlorine } \\
\text { resistance for water desalination }\end{array}$ & PSF & $\begin{array}{l}0.002 \%, 0.02 \% \text { and } \\
0.2 \%\end{array}$ & [161] \\
\hline & carboxymethyl cellulose & - & $\begin{array}{l}\text { Removal of dye and heavy metal for water } \\
\text { treatment } \\
\text { (crystal violet (CV) and cadmium (Cd (II)) ions) }\end{array}$ & PAA & $1.25 \% \mathrm{~W} / \mathrm{V}$ & [178] \\
\hline \multirow{6}{*}{\multicolumn{2}{|c|}{ Polydopamine }} & \multirow{3}{*}{ UF } & $\begin{array}{l}\text { Evaluation of antifouling properties } \\
\text { Model foulant: BSA }\end{array}$ & \multirow[t]{2}{*}{ PSF } & $2 \mathrm{mg} \cdot \mathrm{mL}^{-1}$ & [167] \\
\hline & & & $\begin{array}{l}\text { Evaluation of antifouling properties during } \\
\text { oil/water emulsion filtration }\end{array}$ & & $\begin{array}{l}0.1,0.5,2 \text {, and } 8 \\
\mathrm{mg} / \mathrm{mL}\end{array}$ & [173] \\
\hline & & & $\begin{array}{l}\text { Organic wastewater treatment } \\
\text { Organic solvent: acetone, ether, and formic acid }\end{array}$ & PASS & $1,2,3 \mathrm{~g} / \mathrm{L}$ & [172] \\
\hline & & NF & Separation of water from isopropanol & PVDF & $\begin{array}{l}0.1,0.3,0.50 .7 \text { and } \\
0.9 \mathrm{wt} \%\end{array}$ & [174] \\
\hline & & FO & Removal of salt $(\mathrm{NaCl})$ for water treatment & $\mathrm{PE}$ & $2.0 \mathrm{~g} \cdot \mathrm{L}^{-1}$ & [177] \\
\hline & & RO & $\begin{array}{l}\text { Evaluation of antifouling properties and } \\
\text { desalination } \\
\text { Model foulant: soybean oil }\end{array}$ & - & $2.0 \mathrm{~g} / \mathrm{L}$ & [175] \\
\hline
\end{tabular}


While the advantage of these new membrane and membrane systems to invest in them may not be immediately apparent, the deterioration of competence and reliability of the current desalination techniques appear to far outweigh the costs of investment. However, the adoption of new technologies is mainly depending on the cost effectiveness. In this context, it seems to be more feasible to retrofit and upgrade the existing desalination plants. Thus, future research should be directed to increasing the sustainability in membrane modification. One way of doing this is by using renewable sources/waste for the synthesis of these macromolecules and incorporating innovative and sustainable materials like macromolecules, which is a more efficient and cost-effective technique to produce fresh water of high quality. For example, cellulose is an inexpensive, biodegradable and sustainable polymer as the biomass feedstocks preserve natural resources. Cellulose does not melt or dissolve in normal solvents due to the strong hydrogen bonds that are created between cellulose chains, making them a very good candidate. New sustainable technology and separation processes will be applied with the advent of better materials in this field, a challenge for the current and new generation of material scientists. Therefore, it can be concluded that the macromolecules-modified membranes are one of the best solutions to address many problems associated with membrane technology. Research and development of membrane technology play a crucial role in addressing global water crisis though innovative preparation, processing methods, materials selection and systematic analysis for determining key parameters.

Author Contributions: All authors contributed to the paper. All authors have read and agreed to the published version of the manuscript

Funding: This research was funded by Ministry of Education Malaysia under MRUN Grant (4L862) and FRGS (5F005).

Conflicts of Interest: The authors declare no conflicts of interest.

\section{References}

1. Bolisetty, S.; Peydayesh, M.; Mezzenga, R. Sustainable technologies for water purification from heavy metals: Review and analysis. Chem. Soc. Rev. 2019, 48, 463-487. [CrossRef] [PubMed]

2. Parlar, I.; Hacıfazlıŏlu, M.; Kabay, N.A.L.A.N.; Pek, T.Ö.; Yüksel, M. Performance comparison of reverse osmosis (RO) with integrated nanofiltration (NF) and reverse osmosis process for desalination of MBR effluent. J. Water Process Eng. 2019, 29, 100640. [CrossRef]

3. Nthunya, L.N.; Gutierrez, L.; Derese, S.; Nxumalo, E.N.; Verliefde, A.R.; Mamba, B.B.; Mhlanga, S.D. A review of nanoparticle-enhanced membrane distillation membranes: Membrane synthesis and applications in water treatment. J. Chem. Technol. Biotechnol. 2019, 94, 2757-2771. [CrossRef]

4. Kırtel, O.; Versluys, M.; Van den Ende, W.; Öner, E.T. Fructans of the saline world. Biotechnol. Adv. 2018, 36, 1524-1539. [CrossRef]

5. Esfahani, M.R.; Aktij, S.A.; Dabaghian, Z.; Firouzjaei, M.D.; Rahimpour, A.; Eke, J.; Escobar, I.C.; Abolhassani, M.; Greenlee, L.F.; Esfahani, A.R.; et al. Nanocomposite membranes for water separation and purification: Fabrication, modification, and applications. Sep. Purif. Technol. 2019, 213, 465-499. [CrossRef]

6. Anis, S.F.; Hashaikeh, R.; Hilal, N. Reverse osmosis pretreatment technologies and future trends: A comprehensive review. Desalination 2019, 452, 159-195. [CrossRef]

7. Kavitha, J.; Rajalakshmi, M.; Phani, A.R.; Padaki, M. Pretreatment processes for seawater reverse osmosis desalination systems - A review. J. Water Process Eng. 2019, 32, 100926. [CrossRef]

8. Zhang, Y.; Ruan, H.; Guo, C.; Liao, J.; Shen, J.; Gao, C. Thin-film nanocomposite reverse osmosis membranes with enhanced antibacterial resistance by incorporating p-aminophenol-modified graphene oxide. Sep. Purif. Technol. 2020, 234, 116017. [CrossRef]

9. Buruga, K.; Song, H.; Shang, J.; Bolan, N.; Jagannathan, T.K.; Kim, K.H. A review on functional polymer-clay based nanocomposite membranes for treatment of water. J. Hazard. Mater. 2019, 379, 120584. [CrossRef]

10. Bandara, P.C.; Nadres, E.T.; Peña-Bahamonde, J.; Rodrigues, D.F. Impact of water chemistry, shelf-life, and regeneration in the removal of different chemical and biological contaminants in water by a model Polymeric Graphene Oxide Nanocomposite Membrane Coating. J. Water Process Eng. 2019, 32, 100967. [CrossRef] 
11. Shen, H.; Wang, S.; Xu, H.; Zhou, Y.; Gao, C. Preparation of polyamide thin film nanocomposite membranes containing silica nanoparticles via an in-situ polymerization of SiCl4 in organic solution. J. Membr. Sci. 2018, 565, 145-156. [CrossRef]

12. Fu, S.; Sun, Z.; Huang, P.; Li, Y.; Hu, N. Some basic aspects of polymer nanocomposites: A critical review. Nano Mater. Sci. 2019, 1, 2-30. [CrossRef]

13. Qu, X.; Alvarez, P.J.; Li, Q. Applications of nanotechnology in water and wastewater treatment. Water Res. 2013, 47, 3931-3946. [CrossRef] [PubMed]

14. Crock, C.A.; Rogensues, A.R.; Shan, W.; Tarabara, V.V. Polymer nanocomposites with graphene-based hierarchical fillers as materials for multifunctional water treatment membranes. Water Res. 2013, 47, 3984-3996. [CrossRef]

15. Cay-Durgun, P.; McCloskey, C.; Konecny, J.; Khosravi, A.; Lind, M.L. Evaluation of thin film nanocomposite reverse osmosis membranes for long-term brackish water desalination performance. Desalination 2017, 404, 304-312. [CrossRef]

16. Baek, Y.; Kim, H.J.; Kim, S.H.; Lee, J.C.; Yoon, J. Evaluation of carbon nanotube-polyamide thin-film nanocomposite reverse osmosis membrane: Surface properties, performance characteristics and fouling behavior. J. Ind. Eng. Chem. 2017, 56, 327-334. [CrossRef]

17. Aljundi, I.H. Desalination characteristics of TFN-RO membrane incorporated with ZIF-8 nanoparticles. Desalination 2017, 420, 12-20. [CrossRef]

18. Farahbakhsh, J.; Delnavaz, M.; Vatanpour, V. Investigation of raw and oxidized multiwalled carbon nanotubes in fabrication of reverse osmosis polyamide membranes for improvement in desalination and antifouling properties. Desalination 2017, 410, 1-9. [CrossRef]

19. Singh, S.; Kumar, V.; Romero, R.; Sharma, K.; Singh, J. Applications of Nanoparticles in Wastewater Treatment. In Nanobiotechnology in Bioformulations; Prasad, R., Kumar, V., Kumar, M., Choudhary, D., Eds.; Springer International Publishing: Cham, Switzerland, 2019; pp. 395-418.

20. Kausar, A. Inorganic nanomaterials in polymeric water decontamination membranes. Int. J. Plast. Technol. 2019, 23, 1-11. [CrossRef]

21. Zheng, K.; Setyawati, M.I.; Leong, D.T.; Xie, J. Antimicrobial silver nanomaterials. Coord. Chem. Rev. 2018, 357, 1-17. [CrossRef]

22. Mocanu, A.; Rusen, E.; Diacon, A.; Isopencu, G.; Mustățea, G.; Şomoghi, R.; Dinescu, A. Antimicrobial properties of polysulfone membranes modified with carbon nanofibers and silver nanoparticles. Mater. Chem. Phys. 2019, 223, 39-45. [CrossRef]

23. Lee, E.S.; Kim, Y.O.; Ha, Y.M.; Lim, D.; Hwang, J.Y.; Kim, J.; Park, M.; Cho, J.W.; Jung, Y.C. Antimicrobial properties of lignin-decorated thin multi-walled carbon nanotubes in poly (vinyl alcohol) nanocomposites. Eur. Polym. J. 2018, 105, 79-84. [CrossRef]

24. Wang, W.; Zhu, L.; Shan, B.; Xie, C.; Liu, C.; Cui, F.; Li, G. Preparation and characterization of SLS-CNT/PES ultrafiltration membrane with antifouling and antibacterial properties. J. Membr. Sci. 2018, 548, 459-469. [CrossRef]

25. Ali, S.; Rehman, S.A.U.; Luan, H.Y.; Farid, M.U.; Huang, H. Challenges and opportunities in functional carbon nanotubes for membrane-based water treatment and desalination. Sci. Total Environ. 2019, 646, 1126-1139. [CrossRef]

26. Henriques, P.C.; Borges, I.; Pinto, A.M.; Magalhães, F.D.; Gonçalves, I.C. Fabrication and antimicrobial performance of surfaces integrating graphene-based materials. Carbon 2018, 132, 709-732. [CrossRef]

27. Han, W.; Wu, Z.; Li, Y.; Wang, Y. Graphene family nanomaterials (GFNs)_promising materials for antimicrobial coating and film: A review. Chem. Eng. J. 2019, 358, 1022-1037. [CrossRef]

28. Ren, T.; Wang, Y.; Yu, Q.; Li, M. Synthesis of antimicrobial peptide-grafted graphene oxide nanosheets with high antimicrobial efficacy. Mater. Lett. 2019, 235, 42-45. [CrossRef]

29. Onitsuka, S.; Hamada, T.; Okamura, H. Preparation of antimicrobial gold and silver nanoparticles from tea leaf extracts. Colloids Surf. B Biointerfaces 2019, 173, 242-248. [CrossRef]

30. Cano, A.P.; Gillado, A.V.; Montecillo, A.D.; Herrera, M.U. Copper sulfate-embedded and copper oxide-embedded filter paper and their antimicrobial properties. Mater. Chem. Phys. 2018, 207, 147-153. [CrossRef] 
31. Pasquet, J.; Chevalier, Y.; Pelletier, J.; Couval, E.; Bouvier, D.; Bolzinger, M.A. The contribution of zinc ions to the antimicrobial activity of zinc oxide. Colloids Surfaces A Physicochem. Eng. Asp. 2014, 457, 263-274. [CrossRef]

32. Zhao, Q.; Wang, M.; Yang, H.; Shi, D.; Wang, Y. Preparation, characterization and the antimicrobial properties of metal ion-doped TiO2 nano-powders. Ceram. Int. 2018, 44, 5145-5154. [CrossRef]

33. Dutta, P.; Wang, B. Zeolite-supported silver as antimicrobial agents. Coord. Chem. Rev. 2019, 383, 1-29. [CrossRef]

34. Ji, Y.L.; Qian, W.J.; An, Q.F.; Huang, S.H.; Lee, K.R.; Gao, C.J. Mussel-inspired zwitterionic dopamine nanoparticles as building blocks for constructing salt selective nanocomposite membranes. J. Membr. Sci. 2019, 572, 140-151. [CrossRef]

35. Akther, N.; Phuntsho, S.; Chen, Y.; Ghaffour, N.; Shon, H.K. Recent advances in nanomaterial-modified polyamide thin-film composite membranes for forward osmosis processes. J. Membr. Sci. 2019, 584, $20-45$. [CrossRef]

36. Saleem, H.; Zaidi, S.J. Nanoparticles in reverse osmosis membranes for desalination: A state of the art review. Desalination 2020, 475, 114171. [CrossRef]

37. Ahmaruzzaman, M. Nano-materials: Novel and Promising Adsorbents for Water Treatment. Asian J. Water Environ. Pollut. 2019, 16, 43-53. [CrossRef]

38. Akhavan, O.; Ghaderi, E. Toxicity of graphene and graphene oxide nanowalls against bacteria. ACS Nano 2010, 4, 5731-5736. [CrossRef]

39. Jia, G.; Wang, H.; Yan, L.; Wang, X.; Pei, R.; Yan, T.; Zhao, Y.; Guo, X. Cytotoxicity of carbon nanomaterials: Single-wall nanotube, multi-wall nanotube, and fullerene. Environ. Sci. Technol. 2005, 39, 1378-1383. [CrossRef]

40. Ahamed, M.; AlSalhi, M.S.; Siddiqui, M.K.J. Silver nanoparticle applications and human health. Clin. Chim. Acta 2010, 411, 1841-1848. [CrossRef]

41. Upadhyaya, L.; Qian, X.; Wickramasinghe, S.R. Chemical modification of membrane surface-overview. Curr. Opin. Chem. Eng. 2018, 20, 13-18. [CrossRef]

42. Yang, Z.; Ma, X.H.; Tang, C.Y. Recent development of novel membranes for desalination. Desalination 2018, 434, 37-59. [CrossRef]

43. Haider, M.S.; Shao, G.N.; Imran, S.M.; Park, S.S.; Abbas, N.; Tahir, M.S.; Hussain, M.; Bae, W.; Kim, H.T. Aminated polyethersulfone-silver nanoparticles (AgNPs-APES) composite membranes with controlled silver ion release for antibacterial and water treatment applications. Mater. Sci. Eng. C 2016, 62, 732-745. [CrossRef]

44. Marinescu, I.D.; Rowe, W.B.; Dimitrov, B.; Inaski, I. 16-Processed Materials. In Tribology of Abrasive Machining Processes; Marinescu, I.D., Rowe, W.B., Dimitrov, B., Inasaki, I., Eds.; William Andrew Publishing: Norwich, NY, USA, 2004; pp. 635-663.

45. Shrivastava, A. 2-Polymerization. In Introduction to Plastics Engineering; Shrivastava, A., Ed.; William Andrew Publishing: Norwich, NY, USA, 2018; pp. 17-48.

46. Ab Hamid, N.H.; Ye, L.; Wang, D.K.; Smart, S.; Filloux, E.; Lebouteiller, T.; Zhang, X. Evaluating the membrane fouling formation and chemical cleaning strategy in forward osmosis membrane filtration treating domestic sewage. Environ. Sci. Water Res. Technol. 2018, 4, 2092-2103. [CrossRef]

47. Li, J.; Wei, M.; Wang, Y. Substrate matters: The influences of substrate layers on the performances of thin-film composite reverse osmosis membranes. Chin. J. Chem. Eng. 2017, 25, 1676-1684. [CrossRef]

48. Yang, Z.; Zhou, Y.; Feng, Z.; Rui, X.; Zhang, T.; Zhang, Z. A Review on Reverse Osmosis and Nanofiltration Membranes for Water Purification. Polymers 2019, 11, 1252. [CrossRef]

49. Fathizadeh, M.; Tien, H.N.; Khivantsev, K.; Song, Z.; Zhou, F.; Yu, M. Polyamide/nitrogen-doped graphene oxide quantum dots (N-GOQD) thin film nanocomposite reverse osmosis membranes for high flux desalination. Desalination 2019, 451, 125-132. [CrossRef]

50. Aziz, M.; Kasongo, G. Scaling prevention of thin film composite polyamide Reverse Osmosis membranes by Zn ions. Desalination 2019, 464, 76-83. [CrossRef]

51. Jamaly, S.; Darwish, N.N.; Ahmed, I.; Hasan, S.W. A short review on reverse osmosis pretreatment technologies. Desalination 2014, 354, 30-38. [CrossRef]

52. Qasim, M.; Badrelzaman, M.; Darwish, N.N.; Darwish, N.A.; Hilal, N. Reverse osmosis desalination: A state-of-the-art review. Desalination 2019, 459, 59-104. [CrossRef] 
53. Le, N.L.; Nunes, S.P. Materials and membrane technologies for water and energy sustainability. Sustain. Mater. Technol. 2016, 7, 1-28. [CrossRef]

54. Nasir, A.; Masood, F.; Yasin, T.; Hameed, A. Progress in polymeric nanocomposite membranes for wastewater treatment: Preparation, properties and applications. J. Ind. Eng. Chem. 2019, 79, 29-40. [CrossRef]

55. Goh, P.S.; Matsuura, T.; Ismail, A.F.; Hilal, N. Recent trends in membranes and membrane processes for desalination. Desalination 2016, 391, 43-60. [CrossRef]

56. Wen, Y.; Yuan, J.; Ma, X.; Wang, S.; Liu, Y. Polymeric nanocomposite membranes for water treatment: A review. Environ. Chem. Lett. 2019, 17, 1539-1551. [CrossRef]

57. Zhu, J.; Hou, J.; Zhang, Y.; Tian, M.; He, T.; Liu, J.; Chen, V. Polymeric antimicrobial membranes enabled by nanomaterials for water treatment. J. Membr. Sci. 2018, 550, 173-197. [CrossRef]

58. Tan, X.; Rodrigue, D. A Review on Porous Polymeric Membrane Preparation. Part I: Production Techniques with Polysulfone and Poly (Vinylidene Fluoride). Polymers 2019, 11, 1160. [CrossRef]

59. Ashraf, M.A.; Maah, M.J.; Qureshi, A.K.; Gharibreza, M.; Yusoff, I. Synthetic polymer composite membrane for the desalination of saline water. Desalin. Water Treat. 2013, 51, 3650-3661. [CrossRef]

60. Kang, G.D.; Cao, Y.M. Development of antifouling reverse osmosis membranes for water treatment: A review. Water Res. 2012, 46, 584-600. [CrossRef]

61. González-Gago, C.; Pisonero, J.; Sandín, R.; Fuertes, J.F.; Sanz-Medel, A.; Bordel, N. Analytical potential of rf-PGD-TOFMS for depth profiling of an oxidized thin film composite. J. Anal. At. Spectrom. 2016, 31, 288-296. [CrossRef]

62. Ismail, A.F.; Padaki, M.; Hilal, N.; Matsuura, T.; Lau, W.J. Thin film composite membrane-Recent development and future potential. Desalination 2015, 356, 140-148. [CrossRef]

63. Pendergast, M.M.; Hoek, E.M. A review of water treatment membrane nanotechnologies. Energy Environ. Sci. 2011, 4, 1946-1971. [CrossRef]

64. Ahmad, N.A.; Goh, P.S.; Abdul Karim, Z.; Ismail, A.F. Thin Film Composite Membrane for Oily Waste Water Treatment: Recent Advances and Challenges. Membranes 2018, 8, 86. [CrossRef] [PubMed]

65. Lee, A.; Elam, J.W.; Darling, S.B. Membrane materials for water purification: Design, development, and application. Environmental Science: Water Res. Technol. 2016, 2, 17-42. [CrossRef]

66. Guo, W.; Ngo, H.H.; Li, J. A mini-review on membrane fouling. Bioresour. Technol. 2012, 122, $27-34$. [CrossRef] [PubMed]

67. Wang, Y.N.; Tang, C.Y. Protein fouling of nanofiltration, reverse osmosis, and ultrafiltration membranes-The role of hydrodynamic conditions, solution chemistry, and membrane properties. J. Membr. Sci. 2011, 376, 275-282. [CrossRef]

68. Kim, T.S.; Park, S.H.; Park, D.; Lee, J.H.; Kang, S. Surface immobilization of chlorhexidine on a reverse osmosis membrane for in-situ biofouling control. J. Membr. Sci. 2019, 576, 17-25. [CrossRef]

69. Sim, L.N.; Chong, T.H.; Taheri, A.H.; Sim, S.T.V.; Lai, L.; Krantz, W.B.; Fane, A.G. A review of fouling indices and monitoring techniques for reverse osmosis. Desalination 2018, 434, 169-188. [CrossRef]

70. Chang, Y.R.; Lee, Y.J.; Lee, D.J. Membrane fouling during water or wastewater treatments: Current research updated. J. Taiwan Inst. Chem. Eng. 2019, 94, 88-96. [CrossRef]

71. Ben-Sasson, M.; Zodrow, K.R.; Genggeng, Q.; Kang, Y.; Giannelis, E.P.; Elimelech, M. Surface functionalization of thin-film composite membranes with copper nanoparticles for antimicrobial surface properties. Environ. Sci. Technol. 2013, 48, 384-393. [CrossRef]

72. Bucs, S.S.; Farhat, N.; Kruithof, J.C.; Picioreanu, C.; van Loosdrecht, M.C.; Vrouwenvelder, J.S. Review on strategies for biofouling mitigation in spiral wound membrane systems. Desalination 2018, 434, 189-197. [CrossRef]

73. Fane, A.G. A grand challenge for membrane desalination: More water, less carbon. Desalination 2018, 426, 155-163. [CrossRef]

74. Goh, P.S.; Lau, W.J.; Othman, M.H.D.; Ismail, A.F. Membrane fouling in desalination and its mitigation strategies. Desalination 2018, 425, 130-155. [CrossRef]

75. Zhang, R.Y.; Liu, M.; He, Y.; Su, X.; Zhao, M. Elimelech and Z. Jiang. Antifouling membranes for sustainable water purification: Strategies and mechanisms. Chem. Soc. Rev. 2016, 45, 5888-5924. [CrossRef]

76. Shahmirzadi, M.A.A.; Kargari, A. 9-Nanocomposite membranes. In Emerging Technologies for Sustainable Desalination Handbook; Gude, V.G., Ed.; Butterworth-Heinemann: Oxford UK, 2018; pp. 285-330. 
77. Zare, S.; Kargari, A. 4-Membrane properties in membrane distillation. In Emerging Technologies for Sustainable Desalination Handbook; Gude, V.G., Ed.; Butterworth-Heinemann: Oxford UK, 2018; pp. 107-156.

78. Hu, W. Polymer Physics: A Molecular Approach. Available online: https://doi.org/10.1016/B978-0-12-815818-0. 00004-7 (accessed on 20 December 2019).

79. Staudinger, H. From Organic Chemistry to Macromolecules. Available online: http://agris.fao.org/agris-search/ search.do?recordID=US201300469664 (accessed on 18 December 2019).

80. Sarkar, A.; Carver, P.I.; Zhang, T.; Merrington, A.; Bruza, K.J.; Rousseau, J.L.; Keinath, S.E.; Dvornic, P.R. Dendrimer-based coatings for surface modification of polyamide reverse osmosis membranes. J. Membr. Sci. 2010, 349, 421-428. [CrossRef]

81. Zhu, W.P.; Gao, J.; Sun, S.P.; Zhang, S.; Chung, T.S. Poly(amidoamine) dendrimer (PAMAM) grafted on thin film composite (TFC) nanofiltration (NF) hollow fiber membranes for heavy metal removal. J. Membr. Sci. 2015, 487, 117-126. [CrossRef]

82. Ghasempour, A.; Pajootan, E.; Bahrami, H.; Arami, M. Introduction of amine terminated dendritic structure to graphene oxide using Poly(propylene Imine) dendrimer to evaluate its organic contaminant removal. J. Taiwan Inst. Chem. Eng. 2017, 71, 285-297. [CrossRef]

83. Bao, X.; Wu, Q.; Shi, W.; Wang, W.; Yu, H.; Zhu, Z.; Zhang, X.; Zhang, Z.; Zhang, R.; Cui, F. Polyamidoamine dendrimer grafted forward osmosis membrane with superior ammonia selectivity and robust antifouling capacity for domestic wastewater concentration. Water Res. 2019, 153, 1-10. [CrossRef]

84. Zhang, X.; Wang, Z.; Tang, C.Y.; Ma, J.; Liu, M.; Ping, M.; Chen, M.; Wu, Z. Modification of microfiltration membranes by alkoxysilane polycondensation induced quaternary ammonium compounds grafting for biofouling mitigation. J. Membr. Sci. 2018, 549, 165-172. [CrossRef]

85. Ping, M.; Zhang, X.; Liu, M.; Wu, Z.; Wang, Z. Surface modification of polyvinylidene fluoride membrane by atom-transfer radical-polymerization of quaternary ammonium compound for mitigating biofouling. J. Membr. Sci. 2019, 570, 286-293. [CrossRef]

86. Cihanoğlu, A.; Altinkaya, S.A. A facile route to the preparation of antibacterial polysulfone-sulfonated polyethersulfone ultrafiltration membranes using a cationic surfactant cetyltrimethylammonium bromide. J. Membr. Sci. 2020, 594, 117438. [CrossRef]

87. Han, L.; Tan, Y.Z.; Xu, C.; Xiao, T.; Trinh, T.A.; Chew, J.W. Zwitterionic grafting of sulfobetaine methacrylate (SBMA) on hydrophobic PVDF membranes for enhanced anti-fouling and anti-wetting in the membrane distillation of oil emulsions. J. Membr. Sci. 2019, 588, 117196. [CrossRef]

88. Chiao, Y.H.; Chen, S.T.; Patra, T.; Hsu, C.H.; Sengupta, A.; Hung, W.S.; Huang, S.H.; Qian, X.; Wickramasinghe, R.; Chang, Y.; et al. Zwitterionic forward osmosis membrane modified by fast second interfacial polymerization with enhanced antifouling and antimicrobial properties for produced water pretreatment. Desalination 2019, 469, 114090. [CrossRef]

89. Zhang, X.; Tian, J.; Gao, S.; Shi, W.; Zhang, Z.; Cui, F.; Zhang, S.; Guo, S.; Yang, X.; Xie, H.; et al. Surface functionalization of TFC FO membranes with zwitterionic polymers: Improvement of antifouling and salt-responsive cleaning properties. J. Membr. Sci 2017, 544, 368-377. [CrossRef]

90. Shi, J.; Kang, H.; Li, N.; Teng, K.; Sun, W.; Xu, Z.; Qian, X.; Liu, Q. Chitosan sub-layer binding and bridging for nanofiber-based composite forward osmosis membrane. Appl. Surf. Sci. 2019, 478, 38-48. [CrossRef]

91. Kebria, M.R.S.; Rahimpour, A.; Bakeri, G.; Abedini, R. Experimental and theoretical investigation of thin ZIF-8/chitosan coated layer on air gap membrane distillation performance of PVDF membrane. Desalination 2019, 450, 21-32. [CrossRef]

92. Elizalde, C.N.B.; Al-Gharabli, S.; Kujawa, J.; Mavukkandy, M.; Hasan, S.W.; Arafat, H.A. Fabrication of blend polyvinylidene fluoride/chitosan membranes for enhanced flux and fouling resistance. Sep. Purif. Technol. 2018, 190, 68-76. [CrossRef]

93. Wang, X.; Cheng, W.; Wang, D.; Ni, X.; Han, G. Electrospun polyvinylidene fluoride-based fibrous nanocomposite membranes reinforced by cellulose nanocrystals for efficient separation of water-in-oil emulsions. J. Membr. Sci. 2019, 575, 71-79. [CrossRef]

94. Moeinzadeh, R.; Ghadam, A.G.J.; Lau, W.J.; Emadzadeh, D. Synthesis of nanocomposite membrane incorporated with amino-functionalized nanocrystalline cellulose for refinery wastewater treatment. Carbohydr. Polym. 2019, 225, 115212. [CrossRef] 
95. Asempour, F.; Emadzadeh, D.; Matsuura, T.; Kruczek, B. Synthesis and characterization of novel Cellulose Nanocrystals-based Thin Film Nanocomposite membranes for reverse osmosis applications. Desalination 2018, 439, 179-187. [CrossRef]

96. Abbasi, E.; Aval, S.F.; Akbarzadeh, A.; Milani, M.; Nasrabadi, H.T.; Joo, S.W.; Hanifehpour, Y.; Nejati-Koshki, K.; Pashaei-Asl, R. Dendrimers: Synthesis, applications, and properties. Nanoscale Res. Lett. 2014, 9, 247. [CrossRef]

97. Vunain, E.; Mishra, A.K.; Mamba, B.B. Dendrimers, mesoporous silicas and chitosan-based nanosorbents for the removal of heavy-metal ions: A review. Int. J. Biol. Macromol. 2016, 86, 570-586. [CrossRef]

98. Sarkar, A.; Carver, P.I.; Zhang, T.; Merrington, A.; Bruza, K.J.; Rousseau, J.L.; Keinath, S.E.; Dvornic, P.R. Surface Modification of Polyamide Reverse Osmosis Membranes with Hydrophilic Dendritic Polymers; ACS Publications: Washington, DC, USA, 2009.

99. Jiao, Y.; Niu, L.N.; Ma, S.; Li, J.; Tay, F.R.; Chen, J.H. Quaternary ammonium-based biomedical materials: State-of-the-art, toxicological aspects and antimicrobial resistance. Prog. Polym. Sci. 2017, 71, 53-90. [CrossRef]

100. Darling, S.B. Perspective: Interfacial materials at the interface of energy and water. J. Appl. Phys. 2018, 124, 030901. [CrossRef]

101. Karatairi, E.; Darling, S.B. Crises and opportunities at the energy-water interface. MRS Bull. 2018, 43, 404-405. [CrossRef]

102. Ulbricht, M. Advanced functional polymer membranes. Polymer 2006, 47, 2217-2262. [CrossRef]

103. Mansourizadeh, A.; Aslmahdavi, Z.; Ismail, A.F.; Matsuura, T. Blend polyvinylidene fluoride/surface modifying macromolecule hollow fiber membrane contactors for $\mathrm{CO}_{2}$ absorption. Int. J. Greenh. Gas Control 2014, 26, 83-92. [CrossRef]

104. Essalhi, M.; Khayet, M. Surface segregation of fluorinated modifying macromolecule for hydrophobic/hydrophilic membrane preparation and application in air gap and direct contact membrane distillation. J. Membr. Sci. 2012, 417, 163-173. [CrossRef]

105. Prince, J.A.; Rana, D.; Singh, G.; Matsuura, T.; Kai, T.J.; Shanmugasundaram, T.S. Effect of hydrophobic surface modifying macromolecules on differently produced PVDF membranes for direct contact membrane distillation. Chem. Eng. J. 2014, 242, 387-396. [CrossRef]

106. Zhang, Y.; Wan, Y.; Pan, G.; Yan, H.; Yao, X.; Shi, H.; Tang, Y.; Wei, X.; Liu, Y. Surface modification of polyamide reverse osmosis membrane with organic-inorganic hybrid material for antifouling. Appl. Surf. Sci. 2018, 433, 139-148. [CrossRef]

107. Carbone, P.; Müller-Plathe, F. Molecular dynamics simulations of polyaminoamide (PAMAM) dendrimer aggregates: Molecular shape, hydrogen bonds and local dynamics. Soft Matter 2009, 5, 2638-2647. [CrossRef]

108. He, L.; Wu, D.; Tong, M. The influence of different charged poly (amido amine) dendrimer on the transport and deposition of bacteria in porous media. Water Res. 2019, 161, 364-371. [CrossRef]

109. Jeon, I.Y.; Noh, H.J.; Baek, J.B. Hyperbranched Macromolecules: From Synthesis to Applications. Molecules 2018, 23, 657. [CrossRef]

110. Sajid, M.; Nazal, M.K.; Baig, N.; Osman, A.M. Removal of heavy metals and organic pollutants from water using dendritic polymers based adsorbents: A critical review. Sep. Purif. Technol. 2018, 191, 400-423. [CrossRef]

111. Singh, B.; Saini, S.; Lohan, S.; Beg, S. Chapter 3-Systematic Development of Nanocarriers Employing Quality by Design Paradigms. In Nanotechnology-Based Approaches for Targeting and Delivery of Drugs and Genes; Mishra, V., Kesharwani, P., Mohd Amin, M.C.I., Iyer, A., Eds.; Academic Press: Pittsburgh, PA, USA, 2017; pp. 110-148.

112. Sum, J.Y.; Ahmad, A.L.; Ooi, B.S. Synthesis of thin film composite membrane using mixed dendritic poly(amidoamine) and void filling piperazine monomers. J. Membr. Sci. 2014, 466, 183-191. [CrossRef]

113. Mansourpanah, Y.; Jafari, Z. Efficacy of different generations and concentrations of PAMAM-NH2 on the performance and structure of TFC membranes. React. Funct. Polym. 2015, 93, 178-189. [CrossRef]

114. Nikolaeva, D.; Langner, C.; Ghanem, A.; Rehim, M.A.; Voit, B.; Meier-Haack, J. Hydrogel surface modification of reverse osmosis membranes. J. Membr. Sci. 2015, 476, 264-276. [CrossRef]

115. Sun, H.; Zhang, X.; He, Y.; Zhang, D.; Feng, X.; Zhao, Y.; Chen, L. Preparation of PVDF-g-PAA-PAMAM membrane for efficient removal of copper ions. Chem. Eng. Sci. 2019, 209, 115186. [CrossRef] 
116. Wu, H.; Zhang, X.; Zhao, X.T.; Li, K.; Yu, C.Y.; Liu, L.F.; Zhou, Y.F.; Gao, C.J. High flux reverse osmosis membranes fabricated with hyperbranched polymers via novel twice-crosslinked interfacial polymerization method. J. Membr. Sci. 2020, 595, 117480. [CrossRef]

117. Mansourpanah, Y.; Shahebrahimi, H.; Kolvari, E. PEG-modified GO nanosheets, a desired additive to increase the rejection and antifouling characteristics of polyamide thin layer membranes. Chem. Eng. Res. Des. 2015, 104, 530-540. [CrossRef]

118. Liu, M.; Yu, C.; Dong, Z.; Jiang, P.; Lü, Z.; Yu, S.; Gao, C. Improved separation performance and durability of polyamide reverse osmosis membrane in tertiary treatment of textile effluent through grafting monomethoxy-poly(ethylene glycol) brushes. Sep. Purif. Technol. 2019, 209, 443-451. [CrossRef]

119. Mahdavi, H.; Shahalizade, T. Preparation, characterization and performance study of cellulose acetate membranes modified by aliphatic hyperbranched polyester. J. Membr. Sci. 2015, 473, 256-266. [CrossRef]

120. Bao, X.; Wu, Q.; Shi, W.; Wang, W.; Zhu, Z.; Zhang, Z.; Zhang, R.; Zhang, B.; Guo, Y.; Cui, F. Dendritic amine sheltered membrane for simultaneous ammonia selection and fouling mitigation in forward osmosis. $J$. Membr. Sci. 2019, 584, 9-19. [CrossRef]

121. Kong, X.; Zhang, Y.; Zeng, S.Y.; Zhu, B.K.; Zhu, L.P.; Fang, L.F.; Matsuyama, H. Incorporating hyperbranched polyester into cross-linked polyamide layer to enhance both permeability and selectivity of nanofiltration membrane. J. Membr. Sci. 2016, 518, 141-149. [CrossRef]

122. Zhang, C.; Cui, F.; Zeng, G.M.; Jiang, M.; Yang, Z.Z.; Yu, Z.G.; Zhu, M.Y.; Shen, L.Q. Quaternary ammonium compounds (QACs): A review on occurrence, fate and toxicity in the environment. Sci. Total Environ. 2015, 518, 352-362. [CrossRef]

123. Zhang, X.; Ma, J.; Tang, C.Y.; Wang, Z.; Ng, H.Y.; Wu, Z. Antibiofouling polyvinylidene fluoride membrane modified by quaternary ammonium compound: Direct contact-killing versus induced indirect contact-killing. Environ. Sci. Technol. 2016, 50, 5086-5093. [CrossRef]

124. Mulder, I.; Siemens, J.; Sentek, V.; Amelung, W.; Smalla, K.; Jechalke, S. Quaternary ammonium compounds in soil: Implications for antibiotic resistance development. Rev. Environ. Sci. Bio/Technol. 2018, 17, 159-185. [CrossRef]

125. Zhang, X.; Wang, Z.; Chen, M.; Liu, M.; Wu, Z. Polyvinylidene fluoride membrane blended with quaternary ammonium compound for enhancing anti-biofouling properties: Effects of dosage. J. Membr. Sci. 2016, 520, 66-75. [CrossRef]

126. Zhang, X.; Wang, Z.; Chen, M.; Ma, J.; Chen, S.; Wu, Z. Membrane biofouling control using polyvinylidene fluoride membrane blended with quaternary ammonium compound assembled on carbon material. J. Membr. Sci. 2017, 539, 229-237. [CrossRef]

127. Fei, P.; Liao, L.; Meng, J.; Cheng, B.; Hu, X.; Song, J. Non-leaching antibacterial cellulose triacetate reverse osmosis membrane via covalent immobilization of quaternary ammonium cations. Carbohydr. Polym. 2018, 181, 1102-1111. [CrossRef]

128. Zheng, L.; Sundaram, H.S.; Wei, Z.; Li, C.; Yuan, Z. Applications of zwitterionic polymers. React. Funct. Polym. 2017, 118, 51-61. [CrossRef]

129. Zheng, L.; Sun, Z.; Li, C.; Wei, Z.; Jain, P.; Wu, K. Progress in biodegradable zwitterionic materials. Polym. Degrad. Stab. 2017, 139, 1-19. [CrossRef]

130. Cao, Z.; Jiang, S. Super-hydrophilic zwitterionic poly (carboxybetaine) and amphiphilic non-ionic poly(ethylene glycol) for stealth nanoparticles. Nano Today 2012, 7, 404-413. [CrossRef]

131. Meng, J.; Cao, Z.; Ni, L.; Zhang, Y.; Wang, X.; Zhang, X.; Liu, E. A novel salt-responsive TFC RO membrane having superior antifouling and easy-cleaning properties. J. Membr. Sci. 2014, 461, 123-129. [CrossRef]

132. Zaidi, S.J.; Mauritz, K.A.; Hassan, M.K. Membrane Surface Modification and Functionalization. In Functional Polymers; Jafar Mazumder, M.A., Sheardown, H., Al-Ahmed, A., Eds.; Springer International Publishing: Cham, Switzerland, 2018; pp. 1-26.

133. Hadidi, M.; Zydney, A.L. Fouling behavior of zwitterionic membranes: Impact of electrostatic and hydrophobic interactions. J. Membr. Sci. 2014, 452, 97-103. [CrossRef]

134. Sun, H.; Zhang, Y.; Sadam, H.; Ma, J.; Bai, Y.; Shen, X.; Kim, J.K.; Shao, L. Novel mussel-inspired zwitterionic hydrophilic polymer to boost membrane water-treatment performance. J. Membr. Sci. 2019, 582, 1-8. [CrossRef] 
135. Kirschner, A.Y.; Chang, C.C.; Kasemset, S.; Emrick, T.; Freeman, B.D. Fouling-resistant ultrafiltration membranes prepared via co-deposition of dopamine/zwitterion composite coatings. J. Membr. Sci. 2017, 541, 300-311. [CrossRef]

136. Ji, Y.L.; An, Q.F.; Guo, Y.S.; Hung, W.S.; Lee, K.R.; Gao, C.J. Bio-inspired fabrication of high perm-selectivity and anti-fouling membranes based on zwitterionic polyelectrolyte nanoparticles. J. Mater. Chem. A 2016, 4, 4224-4231. [CrossRef]

137. You, M.; Wang, P.; Xu, M.; Yuan, T.; Meng, J. Fouling resistance and cleaning efficiency of stimuli-responsive reverse osmosis (RO) membranes. Polymer 2016, 103, 457-467. [CrossRef]

138. Ma, R.; Ji, Y.L.; Weng, X.D.; An, Q.F.; Gao, C.J. High-flux and fouling-resistant reverse osmosis membrane prepared with incorporating zwitterionic amine monomers via interfacial polymerization. Desalination 2016, 381, 100-110. [CrossRef]

139. Zhai, W.; Wang, M.; Song, J.; Zhang, L.; Li, X.M.; He, T. Fouling resistance of 3-[[3-(trimethoxysilane)-propyl] amino] propane-1-sulfonic acid zwitterion modified poly (vinylidene fluoride) membranes. Sep. Purif. Technol. 2020, 116589. [CrossRef]

140. Rabea, E.I.; Badawy, M.E.T.; Stevens, C.V.; Smagghe, G.; Steurbaut, W. Chitosan as Antimicrobial Agent: Applications and Mode of Action. Biomacromolecules 2003, 4, 1457-1465. [CrossRef]

141. Je, J.Y.; Kim, S.K. Chapter 7-Chitosan as Potential Marine Nutraceutical. In Advances in Food and Nutrition Research; Kim, S.-K., Ed.; Academic Press: Pittsburgh, PA, USA, 2012; pp. 121-135.

142. Sabbah, M.; Di Pierro, P.; Cammarota, M.; Dell'Olmo, E.; Arciello, A.; Porta, R. Development and properties of new chitosan-based films plasticized with spermidine and/or glycerol. Food Hydrocoll. 2019, 87, $245-252$. [CrossRef]

143. Daraei, P.; Madaeni, S.S.; Salehi, E.; Ghaemi, N.; Ghari, H.S.; Khadivi, M.A.; Rostami, E. Novel thin film composite membrane fabricated by mixed matrix nanoclay/chitosan on PVDF microfiltration support: Preparation, characterization and performance in dye removal. J. Membr. Sci. 2013, 436, 97-108. [CrossRef]

144. Ekambaram, K.; Doraisamy, M. Surface modification of PVDF nanofiltration membrane using Carboxymethylchitosan-Zinc oxide bionanocomposite for the removal of inorganic salts and humic acid. Colloids Surf. A Physicochem. Eng. Asp. 2017, 525, 49-63. [CrossRef]

145. Ghaemi, N.; Khodakarami, Z. Nano-biopolymer effect on forward osmosis performance of cellulosic membrane: High water flux and low reverse salt. Carbohydr. Polym. 2019, 204, 78-88. [CrossRef]

146. Salehi, H.; Rastgar, M.; Shakeri, A. Anti-fouling and high water permeable forward osmosis membrane fabricated via layer by layer assembly of chitosan/graphene oxide. Appl. Surf. Sci. 2017, 413, 99-108. [CrossRef]

147. Shakeri, A.; Salehi, H.; Rastgar, M. Chitosan-based thin active layer membrane for forward osmosis desalination. Carbohydr. Polym. 2017, 174, 658-668. [CrossRef]

148. Wang, S.; Lu, A.; Zhang, L. Recent advances in regenerated cellulose materials. Prog. Polym. Sci. 2016, 53, 169-206. [CrossRef]

149. Thakur, V.K.; Voicu, S.I. Recent advances in cellulose and chitosan based membranes for water purification: A concise review. Carbohydr. Polym. 2016, 146, 148-165. [CrossRef]

150. Kedia, A.; Dubey, N.K. Chapter 22-Nanoencapsulation of Essential Oils: A Possible Way for an Eco-Friendly Strategy to Control Postharvest Spoilage of Food Commodities from Pests. In Nanomaterials in Plants, Algae, and Microorganisms; Tripathi, D.K., Ahmad, P., Sharma, S., Chauhan, D.K., Duber, N.K., Eds.; Academic Press: Pittsburgh, PA, USA, 2018; pp. 501-522.

151. Habibi, Y.; Lucia, L.A.; Rojas, O.J. Cellulose nanocrystals: Chemistry, self-assembly, and applications. Chem. Rev. 2010, 110, 3479-3500. [CrossRef]

152. Ullah, H.; Wahid, F.; Santos, H.A.; Khan, T. Advances in biomedical and pharmaceutical applications of functional bacterial cellulose-based nanocomposites. Carbohydr. Polym. 2016, 150, 330-352. [CrossRef]

153. Sadasivuni, K.K.; Ponnamma, D.; Ko, H.U.; Kim, H.C.; Zhai, L.; Kim, J. Flexible NO2 sensors from renewable cellulose nanocrystals/iron oxide composites. Sens. Actuators B Chem. 2016, 233, 633-638. [CrossRef]

154. Santamaria-Echart, A.; Ugarte, L.; García-Astrain, C.; Arbelaiz, A.; Corcuera, M.A.; Eceiza, A. Cellulose nanocrystals reinforced environmentally-friendly waterborne polyurethane nanocomposites. Carbohydr. Polym. 2016, 151, 1203-1209. [CrossRef] [PubMed]

155. Peng, B.L.; Dhar, N.; Liu, H.L.; Tam, K.C. Chemistry and applications of nanocrystalline cellulose and its derivatives: A nanotechnology perspective. Can. J. Chem. Eng. 2011, 89, 1191-1206. [CrossRef] 
156. Thakur, V.K.; Singha, A.S.; Thakur, M.K. Natural cellulosic polymers as potential reinforcement in composites: Physicochemical and mechanical studies. Adv. Polym. Technol. 2013, 32, E427-E435. [CrossRef]

157. Nechyporchuk, O.; Belgacem, M.N.; Bras, J. Production of cellulose nanofibrils: A review of recent advances. Ind. Crops Prod. 2016, 93, 2-25. [CrossRef]

158. Brigham, C. Chapter 3.22-Biopolymers: Biodegradable Alternatives to Traditional Plastics. In Green Chemistry; Török, B., Dransfield, T., Eds.; Elsevier: Amsterdam, Netherlands, 2018; pp. 753-770.

159. Zhang, D.; Karkooti, A.; Liu, L.; Sadrzadeh, M.; Thundat, T.; Liu, Y.; Narain, R. Fabrication of antifouling and antibacterial polyethersulfone (PES)/cellulose nanocrystals (CNC) nanocomposite membranes. J. Membr. Sci. 2018, 549, 350-356. [CrossRef]

160. Sobolčiak, P.; Tanvir, A.; Popelka, A.; Moffat, J.; Mahmoud, K.A.; Krupa, I. The preparation, properties and applications of electrospun co-polyamide 6,12 membranes modified by cellulose nanocrystals. Mater. Des. 2017, 132, 314-323. [CrossRef]

161. Liu, S.; Low, Z.X.; Hegab, H.M.; Xie, Z.; Ou, R.; Yang, G.; Simon, G.P.; Zhang, X.; Zhang, L.; Wang, H. Enhancement of desalination performance of thin-film nanocomposite membrane by cellulose nanofibers. J. Membr. Sci. 2019, 592, 117363. [CrossRef]

162. Jonoobi, M.; Ashori, A.; Siracusa, V. Characterization and properties of polyethersulfone/modified cellulose nanocrystals nanocomposite membranes. Polym. Test. 2019, 76, 333-339. [CrossRef]

163. Arena, J.T.; McCloskey, B.; Freeman, B.D.; McCutcheon, J.R. Surface modification of thin film composite membrane support layers with polydopamine: Enabling use of reverse osmosis membranes in pressure retarded osmosis. J. Membr. Sci. 2011, 375, 55-62. [CrossRef]

164. Lee, H.; Dellatore, S.M.; Miller, W.M.; Messersmith, P.B. Mussel-inspired surface chemistry for multifunctional coatings. Science 2007, 318, 426-430. [CrossRef] [PubMed]

165. Lee, H.; Scherer, N.F.; Messersmith, P.B. Single-molecule mechanics of mussel adhesion. Proc. Natl. Acad. Sci. USA 2006, 103, 12999-13003. [CrossRef] [PubMed]

166. Yang, H.C.; Waldman, R.Z.; Wu, M.B.; Hou, J.; Chen, L.; Darling, S.B.; Xu, Z.K. Dopamine: Just the right medicine for membranes. Adv. Funct. Mater. 2018, 28, 1705327. [CrossRef]

167. Tripathi, B.P.; Das, P.; Simon, F.; Stamm, M. Ultralow fouling membranes by surface modification with functional polydopamine. Eur. Polym. J. 2018, 99, 80-89. [CrossRef]

168. Ryu, J.H.; Messersmith, P.B.; Lee, H. Polydopamine Surface Chemistry: A Decade of Discovery. ACS Appl. Mater. Interfaces 2018, 10, 7523-7540. [CrossRef]

169. Ding, Y.H.; Floren, M.; Tan, W. Mussel-inspired polydopamine for bio-surface functionalization. Biosurf. Biotribol. 2016, 2, 121-136. [CrossRef]

170. Ball, V. Polydopamine Nanomaterials: Recent Advances in Synthesis Methods and Applications. Front. Bioeng. Biotechnol. 2018, 6, 109. [CrossRef]

171. Wang, Z.; Yang, H.C.; He, F.; Peng, S.; Li, Y.; Shao, L.; Darling, S.B. Mussel-Inspired Surface Engineering for Water-Remediation Materials. Matter 2019, 1, 115-155. [CrossRef]

172. Xiong, C.; Cao, S.; Wang, Y.; Wang, X.; Long, S.; Zhang, G.; Yang, J. Surface modification of polyarylene sulfide sulfone membrane by coating with polydopamine. J. Coat. Technol. Res. 2019, 16, 643-650. [CrossRef]

173. Kasemset, S.; He, Z.; Miller, D.J.; Freeman, B.D.; Sharma, M.M. Effect of polydopamine deposition conditions on polysulfone ultrafiltration membrane properties and threshold flux during oil/water emulsion filtration. Polymer 2016, 97, 247-257. [CrossRef]

174. Ji, Y.L.; Ang, M.B.M.Y.; Hung, H.C.; Huang, S.H.; An, Q.F.; Lee, K.R.; Lai, J.Y. Bio-inspired deposition of polydopamine on PVDF followed by interfacial cross-linking with trimesoyl chloride as means of preparing composite membranes for isopropanol dehydration. J. Membr. Sci. 2018, 557, 58-66. [CrossRef]

175. Li, Y.; Shi, S.; Cao, H.; Zhao, Z.; Su, C.; Wen, H. Improvement of the antifouling performance and stability of an anion exchange membrane by surface modification with graphene oxide (GO) and polydopamine (PDA). J. Membr. Sci. 2018, 566, 44-53. [CrossRef]

176. Wang, J.; Guo, H.; Shi, X.; Yao, Z.; Qing, W.; Liu, F.; Tang, C.Y. Fast polydopamine coating on reverse osmosis membrane: Process investigation and membrane performance study. J. Colloid Interface Sci. 2019, 535, 239-244. [CrossRef] [PubMed] 
177. Kwon, S.J.; Park, S.H.; Shin, M.G.; Park, M.S.; Park, K.; Hong, S.; Park, H.; Park, Y.I.; Lee, J.H. Fabrication of high performance and durable forward osmosis membranes using mussel-inspired polydopamine-modified polyethylene supports. J. Membr. Sci. 2019, 584, 89-99. [CrossRef]

178. Saber-Samandari, S.; Saber-Samandari, S.; Heydaripour, S.; Abdouss, M. Novel carboxymethyl cellulose based nanocomposite membrane: Synthesis, characterization and application in water treatment. J. Environ. Manag. 2016, 166, 457-465. [CrossRef]

(C) 2020 by the authors. Licensee MDPI, Basel, Switzerland. This article is an open access article distributed under the terms and conditions of the Creative Commons Attribution (CC BY) license (http://creativecommons.org/licenses/by/4.0/). 